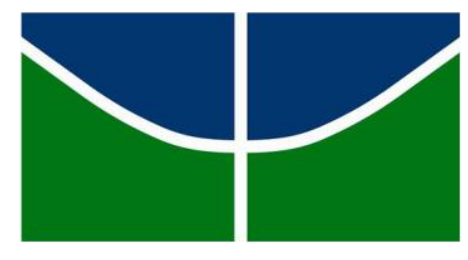

\author{
Universidade de Brasília \\ Instituto de Ciências Biológicas \\ Programa de Pós-Graduação em Zoologia
}

\title{
INFLUÊNCIA DA DENSIDADE NA FERTILIDADE DE Tityus serrulatus \\ LUTZ \& MELO, 1922 (SCORPIONES: BUTHIDAE)
}

\author{
Feliphe de Freitas Novais
}

Brasília/DF 


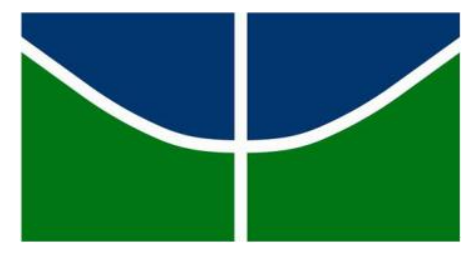

\author{
Universidade de Brasília \\ Instituto de Ciências Biológicas \\ Programa de Pós-Graduação em Zoologia
}

\title{
INFLUÊNCIA DA DENSIDADE NA FERTILIDADE DE Tityus serrulatus LUTZ \& MELO, 1922 (SCORPIONES: BUTHIDAE)
}

Feliphe de Freitas Novais

Dissertação apresentada ao

Programa de Pós-Graduação em

Zoologia como requisito parcial para a obtenção do título de Mestre em Zoologia

Orientador: Paulo César Motta

Brasília/DF 
Feliphe de Freitas Novais

INFLUÊNCIA DA DENSIDADE NA FERTILIDADE DE Tityus serrulatus LUTZ \& MELO, 1922 (SCORPIONES: BUTHIDAE)

Banca Examinadora:

Prof. Dr. Paulo César Motta

Presidente - Programa de Pós-Graduação em Zoologia/UnB

Profa. Dra. Regina Helena F. Macedo

Membro Titular - Programa de Pós-Graduação em Zoologia /UnB

Prof. Dr. Osmindo Rodrigues Pires Júnior

Membro Externo - Programa de Pós-Graduação em Biologia Animal/UnB

Profa. Dra. Marina Regina Frizzas

Membro Suplente - Programa de Pós-Graduação em Zoologia /UnB 
Dedico este trabalho a minha família, meus pais André e Cida, minha namorada Letícia, minha irmã Andréia e a minha eterna parceirinha Lory. 


\section{Agradecimentos}

Agradeço a todos que de alguma forma contribuíram para a conclusão deste trabalho.

Ao Professor Paulo César Motta (Tri), pelo incentivo e auxílio durante o Mestrado e principalmente por ter aberto as portas do Laboratório de Aracnídeos no dia 18 de agosto de 2010, início e decisivo momento para o encaminhamento de minha vida acadêmica.

Aos que me ajudaram nas coletas de campo, abrindo bueiros, caixas de incêndio, galerias de águas pluviais, elétricas e até mesmo "passeios" noturnos em um cemitério buscando este fascinante escorpião. Fica aqui registrado o agradecimento ao meu grande amigo Maurício Macêdo que muito colaborou neste "trabalho sujo" e também com discussões e sugestões, a minha namorada Leticia Carvalho a qual mostrou-se realmente apaixonada aceitando explorar estes locais nada românticos, inimagináveis e pouco desejáveis para tardes de domingo, além de todo apoio durante o mestrado; ao Prof. Diego Campidelli que trocou os livros de História por lanternas UV, potes, pinças e sempre bem humorado, disposto e interessado durante as "missões", assim como o também professor Osvaldo A. Ferreira Junior que deixou um pouco de lado a Geografia e colaborou com a pesquisa. Aos colegas de laboratório, Mariana Vasconcellos por colaborar nas coletas e manutenção dos escorpiões, ao mestrando Ivan K. Malinov por também ajudar na manutenção e no dia-a-dia do laboratório, assim como o também mestrando Augusto Arcela nas coletas, conversas e sugestões, assim como ao colega de mestrado e laboratório Vítor Renan de Paula Ferreira por suas colaborações sapientes, ao Leandro Garcia por toda contribuição ao trabalho e ao Sr. José Duarte que ajudou no corte de muitos tijolos para a montagem do substrato dos cativeiros que abrigaram os escorpiões.

Ao Leonardo Castilho (Leleco) por todo auxílio estatístico e paciência nas inúmeras dúvidas que foram sanadas sempre com enorme clareza e disposição, e também pelas sugestões e discussões pertinentes ao trabalho.

A Professora Ivone Rezende Diniz por emprestar a balança analítica de alta precisão durante todo o trabalho.

A todos os professores do Programa da Pós-Graduação em Zoologia da UnB, uma vez que colaboraram para o desenvolvimento crítico e intelectual, bem como os demais docentes que 
fizeram-se presentes durante minha vida, entre eles o Prof. Dr. Juliano B. Carregaro, grande incentivador e apoiador de pesquisas e da busca pelo conhecimento.

E por fim, porém não menos importantes, todos funcionários do Instituto de Ciências Biológicas.

A FAP-DF pela concessão da bolsa. 


\section{SUMÁRIO}

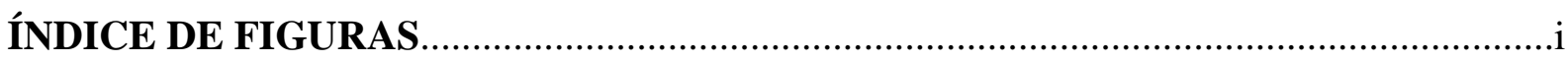

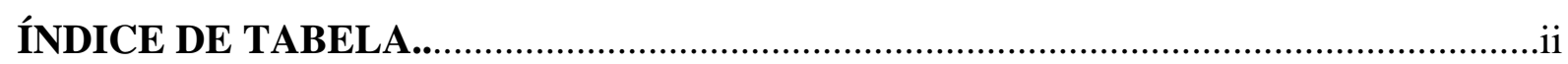

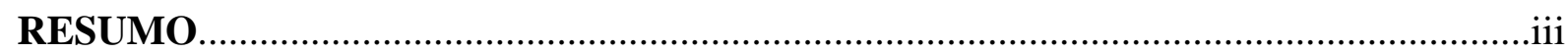

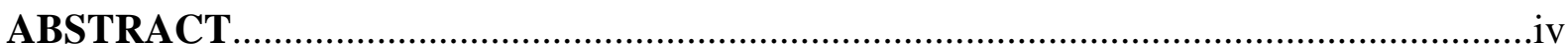

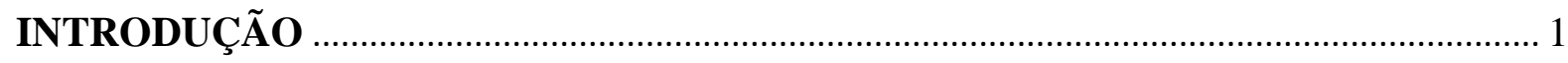

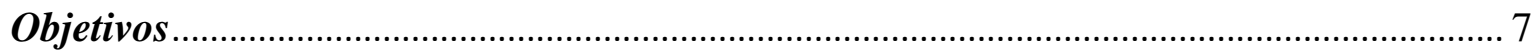

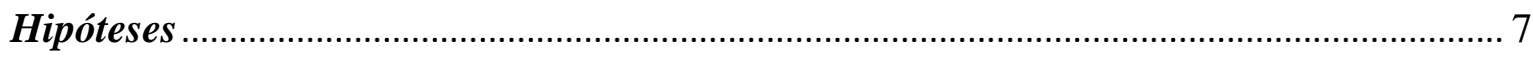

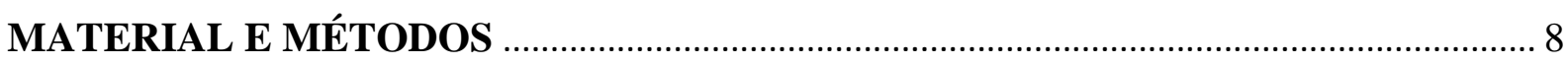

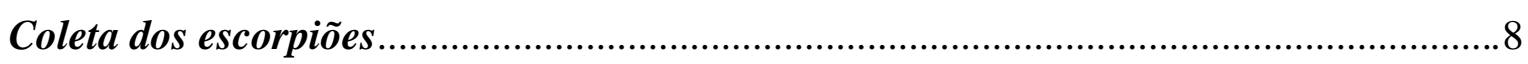

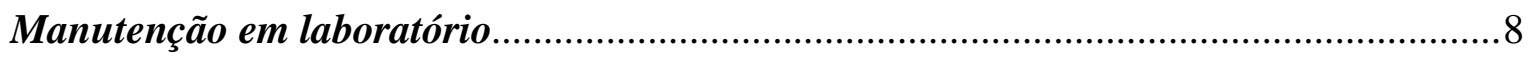

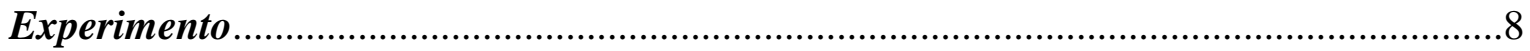

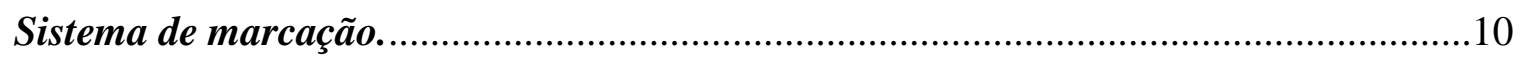

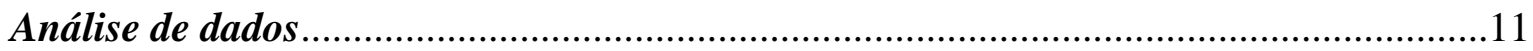

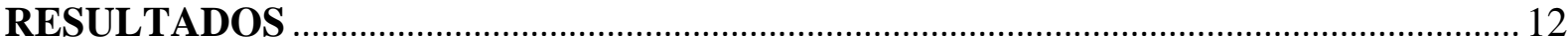

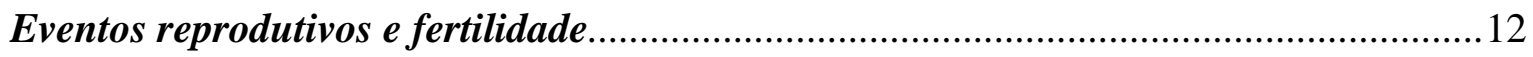

Tamanho da prole e correlações entre adultos e ninhadas............................................14

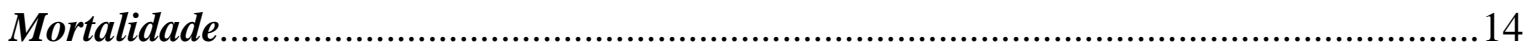

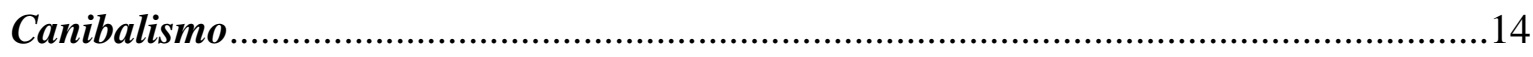

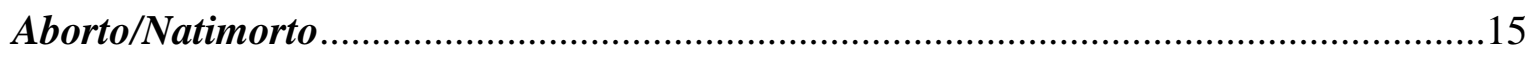

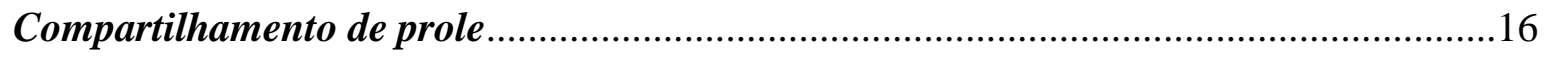

DISCUSSÃO

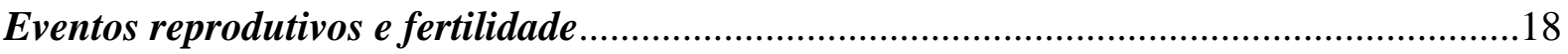

Tamanho da prole e correlações entre adultos e ninhadas ...............................................20

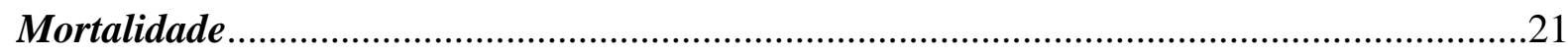

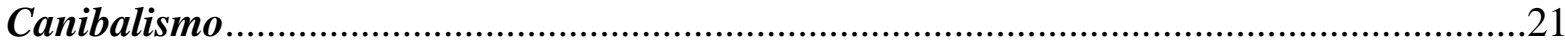

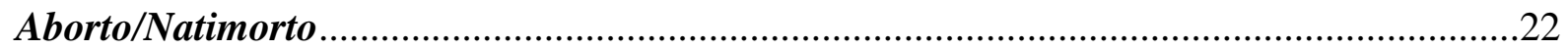


Compartilhamento de prole. .22

CONCLUSÕES.

.24

REFERÊNCIAS.. 


\section{ÍNDICE DE FIGURAS}

Figura 1. Anatomia ventral e dorsal de Tityus serrulatus.

Figura 2. Setas indicando serrilhas dorsais do $3^{\circ}$ e $4^{\circ}$ segmentos metassomais de $T$. serrulatus. 3

Figura 3. Filhotes no dorso da fêmea. (A) Prole de primeiro ínstar, (B) prole de segundo ínstar com indivíduos marcados com tinta vermelha .5

Figura 4. Potes contendo a distribuição de animais por forma de tratamento, onde é possível visualizar o controle, Grupo 1 e Grupo 2, respectivamente

Figura 5. (A) Adulto, (B) filhote do primeiro ínstar tendo o tamanho mensurado através do programa Snake Measure tool.

Figura 6. Exemplo do sistema de marcação utilizado no experimento e indivíduo marcado, respectivamente

Figura 7. Total de eventos reprodutivos ocorridos entre agosto de 2015 a novembro de 2016

Figura 8. Número de eventos reprodutivos por tratamento, entre agosto de 2015 e novembro de 2016

Figura 9. Indivíduo predado logo após ser inserido no grupo 2 .

Figura 10. Adulto de Tityus serrulatus predando filhote recém-nascido. .15

Figura 11. (A) Indivíduo C6 do controle com sua prole recém abortada, (B) ampliação para melhor visualização dos diferentes estágios de formação. .16

Figura 12. Filhotes natimortos do Grupo 2

Figura 13. (A) Filhote do ínstar II em uma fêmea com prole recém nascida, (B) filhote sem marcação junto a prole de outra fêmea 


\section{ÍNDICE DE TABELA}

Número de partos por tratamento. NTF, número total de fêmeas; DNS, densidade por $\mathrm{cm} 2$; NFR, número de fêmeas que reproduziram; NER, número de eventos reprodutivos e FR, fêmeas com mais de uma

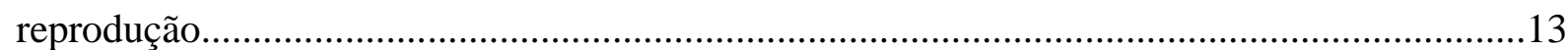




\section{RESUMO}

Foram analisados os efeitos da densidade sobre aspectos reprodutivos do escorpião amarelo Tityus serrulatus Lutz \& Melo, 1922 do Distrito Federal de agosto de 2015 até novembro de 2016. Durante o experimento foram usados 153 escorpiões adultos os quais deram origem a 1.642 filhotes, demonstrando a capacidade reprodutiva desta espécie que a cada dia se torna mais importante no âmbito da saúde pública de nosso país. Os resultados demonstraram efeitos negativos da densidade no número de eventos reprodutivos e na fertilidade dos indivíduos, porém sem afetar o tamanho da ninhada (média de 16,5 filhotes). Também foi observada correlação entre o peso dos adultos e o peso dos filhotes e ausência de correlação entre o número de filhotes por evento reprodutivo e o peso dos adultos. A taxa de mortalidade também sofreu influência da densidade, onde indivíduos presentes em ambientes com maior densidade populacional mostraram-se mais susceptíveis ao óbito. Foram registrados casos de canibalismo, abortos, natimortos e um comportamento inédito para Tityus serrulatus referente a tolerância e compartilhamento de prole.

PALAVRAS-CHAVE: Arachnida, compartilhamento de prole, partenogênese, sinantrópico, reprodução, escorpião amarelo 


\begin{abstract}
We analyzed the effects of density upon reproductive aspects of the yellow scorpion Tityus serrulatus Lutz \& Melo, 1922 of the Distrito Federal from August 2015 to November 2016. During the experiment 153 adult scorpions were used, which gave rise to 1,642 youngs, demonstrating the reproductive capacity of this species, which each day becomes more important in the scope of public health of our country. The results showed negative effects of density on the number of reproductive events and fertility of individuals, but without affecting the litter size (average of 16.5 youngs). There was also a correlation between adult weight and young weight and absence of correlation between number of youngs per reproductive event and adult weight. The mortality rate was also influenced by density, where individuals present in environments with higher population density were more susceptible to death. There were cases of cannibalism, abortions, stillbirths and unprecedented behaviors for Tityus serrulatus regarding tolerance and offspring sharing.
\end{abstract}

KEY WORDS: Arachnida, offspring sharing, parthenogenesis, synanthropic, reproduction, yellow scorpion 


\section{INTRODUÇÃO}

Os escorpiões estão amplamente distribuídos no globo terrestre, não estando presentes apenas na Antártida (Polis, 1990). Geralmente são animais noturnos, durante o dia escondemse em abrigos como troncos, cascas de árvores, sob rochas e buracos no solo. Comumente são encontrados em ambientes terrestres da mais variada cobertura vegetal e tipos climáticos, como desertos e ambientes tropicais (Polis, 1990; Brazil \& Porto, 2010). Alguns escorpiões também apresentam uma grande capacidade sinantrópica, o que pode ocasionar encontros e alguns acidentes com seres humanos e animais domésticos, entretanto nestes ambientes os escorpiões acabam predando artrópodes prejudiciais aos humanos como aranhas e baratas (Brasil, 2009).

Existem diferentes níveis de socialidade, com crescentes níveis de interação e tolerância entre os seres solitários, sub-sociais, sub-sociais intermediários e eusociais (Wilson, 1971; 1975; Polis \& Lourenço, 1986). A tolerância coespecífica geralmente ocorre apenas em determinadas fases da vida dos aracnídeos, tais como a reprodução e nascimento (Burgess \& Uetz, 1982; Higashi \& Rovner, 1975). Alguns escorpiões podem ter alta densidade populacional devido a disponibilidade de alimentos, sendo assim mais tolerantes com coespecíficos (Polis, 1990).

As agregações entre os animais podem ser benéficas em diversos aspectos, tais como proteção contra a predação, parasitoides, divisão de tarefas e o aumento do sucesso na captura de presas, mesmo que o nível de interação entre os indivíduos do agregado seja pouco ou até mesmo nulo (Alexander, 1974; Uetz \& Hieber, 1994, 1997; Uetz et al., 2002). Em contrapartida, a ausência de alimento pode ser um fator determinante para o aumento da competição intraespecífica, agressão e até mesmo afetar o tamanho do agregado (Rypstra, 1985). O agregado também pode ser considerado um "chamarisco" para predadores, uma vez que sua visualização torna-se mais fácil, devido à alta densidade de indivíduos (Hamilton, 1971; Wilson, 1975). Embora os escorpiões sejam animais na maioria das vezes solitários, limitações ambientais podem propiciar a tolerância intraespecífica (Brownell \& Polis, 2001).

Agregação, comportamento social e cuidado parental ao longo e após a maturação sexual em escorpiões foram observados, por exemplo, em Pandinus imperator Koch, 1841 (Mahsberg, 1990), Heterometrus fulvipes Koch, 1837 (Shivashankar, 1994) e Opisthacanthus 
cayaporum Vellard, 1932 (Lourenço, 2002), e podem ser considerados comportamentos vantajosos para escorpiões de ambientes naturais (Polis \& Lourenço, 1986).

Os escorpiões estão presentes em todo o território nacional, distribuídos em 131 espécies, 23 gêneros e quatro famílias descritas para o Brasil. O gênero Tityus C.L. Koch, 1836 (Buthidae) com 54 espécies é o que desperta maior interesse médico no país (Eickstedt, 1996; Brazil \& Porto, 2010) e na América do Sul (Lourenço \& Eickstedt, 1981). O escorpião amarelo Tityus serrulatus Lutz \& Mello, 1922 está relacionado a maioria dos acidentes com animais peçonhentos no Brasil, sendo apontado como um dos escorpiões mais perigosos não só do Brasil e da América do Sul, mas também de todo o hemisfério sul do planeta (Lourenço \& Eickstedt, 1981; Cupo et al., 1994; Eickstedt et al., 1994; Bucaretchi et al., 1995; Eickstedt et al., 1996; Brazil \& Porto, 2010). Segundo Silva e colaboradores (2015) entre 2009 e 2013 foram registrados 301.854 acidentes com escorpiões no Brasil (média de 60.370 casos por ano), com uma letalidade de $0,13 \%$, o que resultou em cerca de 80 mortes por ano. Os últimos dados do Ministério da Saúde (2015) registram 660 mil acidentes entre os anos de 2000-2015 e 1.026 óbitos, sendo possível observar um padrão crescente tanto no número de acidentes como de óbitos envolvendo escorpiões no Brasil. No ano de 2000 foram registrados 12.552 acidentes e 13 óbitos; 2014 foi o ano recorde em acidentes, com 88.437 acidentes e 82 óbitos; ficando 2015 com 74.598 casos porém com o recorde de 119 óbitos. Os dados dos anos de 2013 até 2015 constam como sujeitos a revisão.

No Distrito Federal, o número de acidentes com escorpiões tem acompanhado o aumento registrado no cenário nacional (Silva, 2015; Ministério da Saúde, 2015). Segundo a Gerência de Vigilância Epidemiológica e Imunização (comunicação pessoal, 01.12.16), novembro tem sido o mês com maior número de acidentes, onde, de 2012 até 2016 ocorreram 305 acidentes, seguido pelos meses de setembro (244) e outubro (263). Para o período dos 5 anos contabilizados, foram 2.605 acidentes no Distrito Federal.

Escorpiões possuem anatomia corporal inconfundível (Fig. 1), com seis pares de apêndices, sendo um par de quelíceras, um par de pedipalpos quelados, quatro pares de pernas; com cefalotórax pequeno e abdômen dividido em duas partes, o pré-abdômen com sete segmentos enquanto o pós-abdômen apresenta cinco segmentos, mais o télson com o aguilhão. Outra característica marcante é a presença de um par de pentes ventral (órgão sensorial) (Polis, 1990). Tityus serrulatus é um escorpião de médio porte, tendo cerca de sete 
centímetros, pedipalpos, pernas, mesossoma e prossoma (ventral) amarelos, prossoma e messoma com dorso marrom escuro, sendo observada serrilha dorsal no $3^{\circ}$ e $4^{\circ}$ segmentos do metassoma (Fig. 2), télson e aguilhão pouco avantajados.

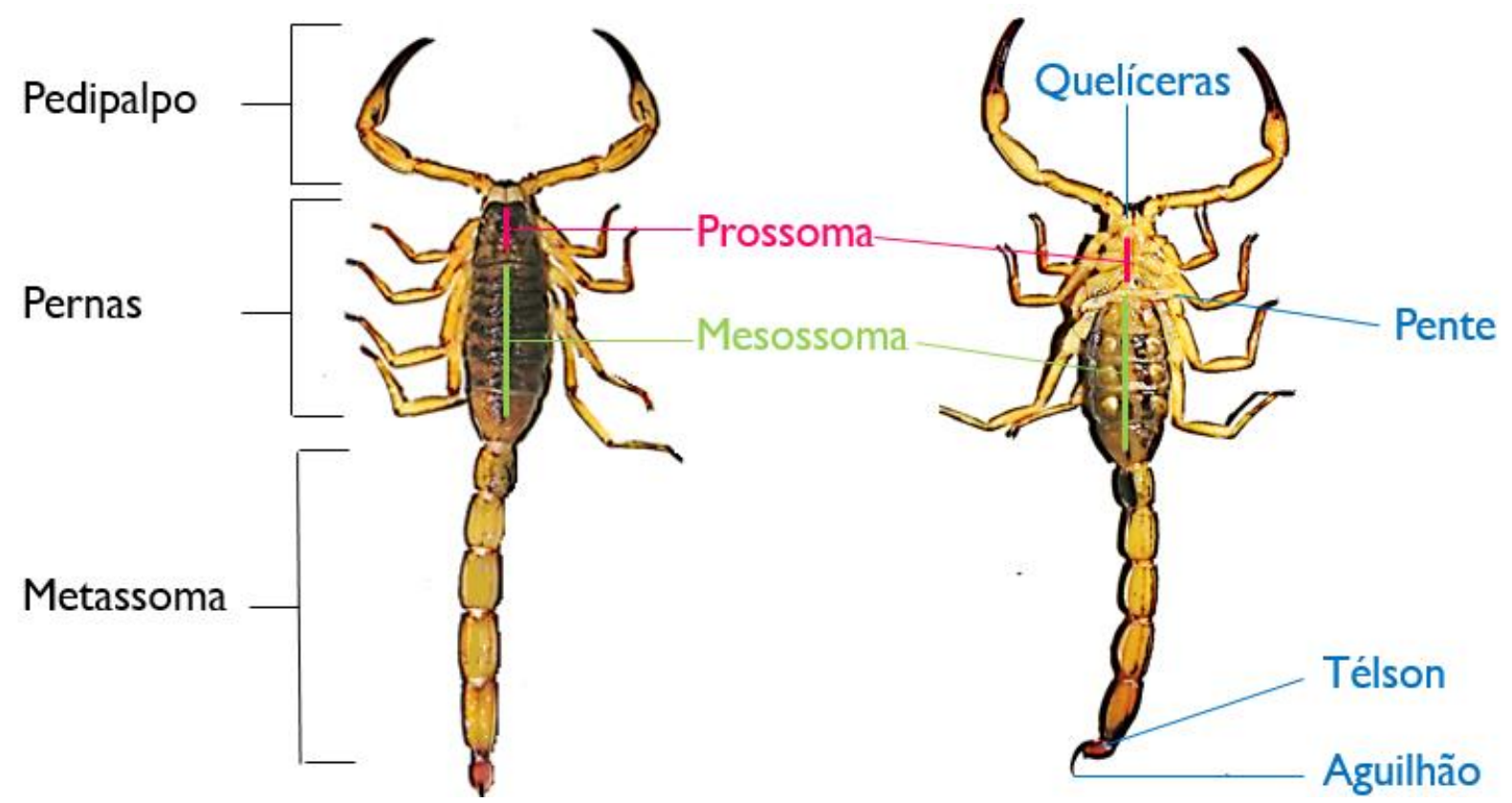

Figura 1. Anatomia ventral e dorsal de Tityus serrulatus.

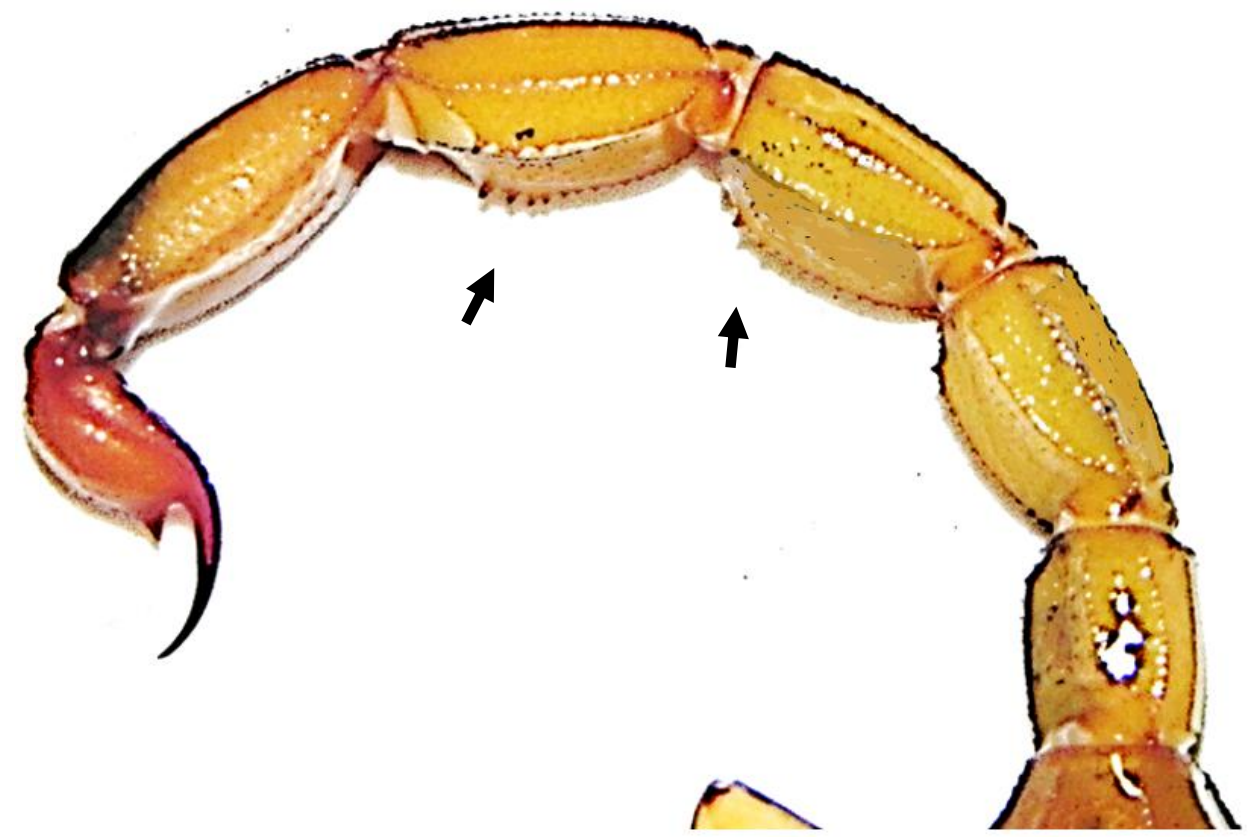

Figura 2. Setas indicando serrilhas dorsais do $3^{\circ}$ e $4^{\circ}$ segmentos metassomais de $T$. serrulatus. 
A reprodução ocorre através de partenogênese (Matthiesen, 1962), onde os óvulos se desenvolvem sem fecundação de um macho. Embora exista conhecimento de populações compostas por machos e fêmeas (Lourenço \& Cloudsley-Thompson, 1999; Souza et al., 2009), ainda não se tem registros publicados da reprodução sexuada para a espécie, sendo a estratégia reprodutiva (partenogênese) apontada como um dos fatores determinantes para seu alto índice de colonização, visto que se comparado com outras espécies acaba tendo vantagens competitivas (Knox, 1997). Foi observado mais de um evento reprodutivo ao ano para Tityus serrulatus (Matthiesen 1971; Outeda-Jorge, 2009; Motta, 2014).

As populações compostas apenas por fêmeas, as quais se reproduzem por meio da partenogênese possuem ampla distribuição no Brasil, ocorrendo em inúmeras cidades da região Sudeste (ES, MG, RJ, SP), Centro-oeste (DF, GO, MS), Nordeste (BA, CE, PE, PI, RN, SE), Sul (SC, PR), ocorrendo também com menor intensidade no Rio Grande do Sul (Brasil, 2009; Souza et al., 2009). Existem registros até mesmo para o norte da Argentina e do Uruguai (Camargo \& Ricciardi, 2000). Os registros referentes as populações com ocorrência de indivíduos de ambos os sexos estão restritas ao Sudeste do Brasil, na região norte de Minas Gerais, na cidade de Espinosa (Lourenço \& Cloudsley-Thompson, 1999; Souza et al., 2009) e no nordeste brasileiro, no oeste do estado da Bahia em São Desidério (Santos, 2014). A ocorrência de $T$. serrulatus em grande parte do território nacional deve-se ao fato de ser um a espécie sinantrópica (Brasil, 2009) e a aspectos relacionados à sua biologia reprodutiva (Lourenço, 2000), estando assim frequentemente em contato com os seres humanos.

Tityus serrulatus foi a primeira espécie de escorpião do mundo a ser descrita como partenogenética (Matthiesen, 1962), e durante um tempo foi considerada inclusive partenogenética obrigatória, onde acreditava-se na existência apenas de fêmeas (Lourenço \& Cuellar, 1995). Entretanto, conforme citado anteriormente, estudos demonstram a existência de populações com indivíduos de ambos os sexos para a espécie. A palavra partenogênese origina-se do grego, onde "parthenos" significa virgem e "genesis" origem, é um tipo de reprodução que envolve a produção de novos indivíduos por fêmeas não fecundadas (Brusca \& Brusca, 2003; Futuyma, 2005). Tityus serrulatus é uma espécie que apresenta telitoquia (originando apenas fêmeas) e apomixia (formação de gametas sem meiose, originando indivíduos diplóides geneticamente idênticos à mãe, exceto por eventuais mutações) (Lourenço; 2008; Schneider \& Cella, 2010). Este escorpião também é considerado como uma espécie oportunista que prolifera rapidamente em ambientes instáveis, apresentando a 
estratégia reprodutiva do tipo " $\mathrm{r}$ ", ao contrário de muitos outros escorpiões que apresentam estratégia do tipo "k" (MacArthur \& Wilson, 1967; Polis, 1990; Lourenço, 1991, 2000; Lourenço \& Cuellar, 1995).

A utilização de diversos tipos de abrigos (tubulações, esgotos, bueiros, caixas de incêndio e telefone, etc.), a abundância de alimento (baratas), a ausência ou escassez de predadores naturais nestes locais, o tipo de reprodução (partenogênese e iteroparidae - podem ter dois a três partos por ano, geralmente com 10 a 20 filhotes por parto), e a eventual tolerância a outros indivíduos da mesma espécie, aparentemente com canibalismo reduzido, são importantes aspectos que ajudam a explicar o sucesso deste escorpião em ambientes urbanos (Motta, 2014). Além de todas estas características biológicas que propiciam o grande sucesso em ambientes urbanos, ele praticamente não é afetado pelo controle químico (Albuquerque et al., 2009).

Tityus serrulatus tem como comportamento manter a prole em seu dorso durante determinado período, geralmente até o fim do primeiro ínstar o que dura cerca de 6 a 11 dias, comportamento comum neste grupo (Brownell \& Polis, 2001). Entretanto, também é possível observar indivíduos do segundo ínstar no dorso das fêmeas (Fig. 3), e para que isto ocorra é necessário o reconhecimento entre os envolvidos, a fim de evitar que sejam confundidos com predadores, presas e indivíduos de outras espécies (Kullmann, 1972).

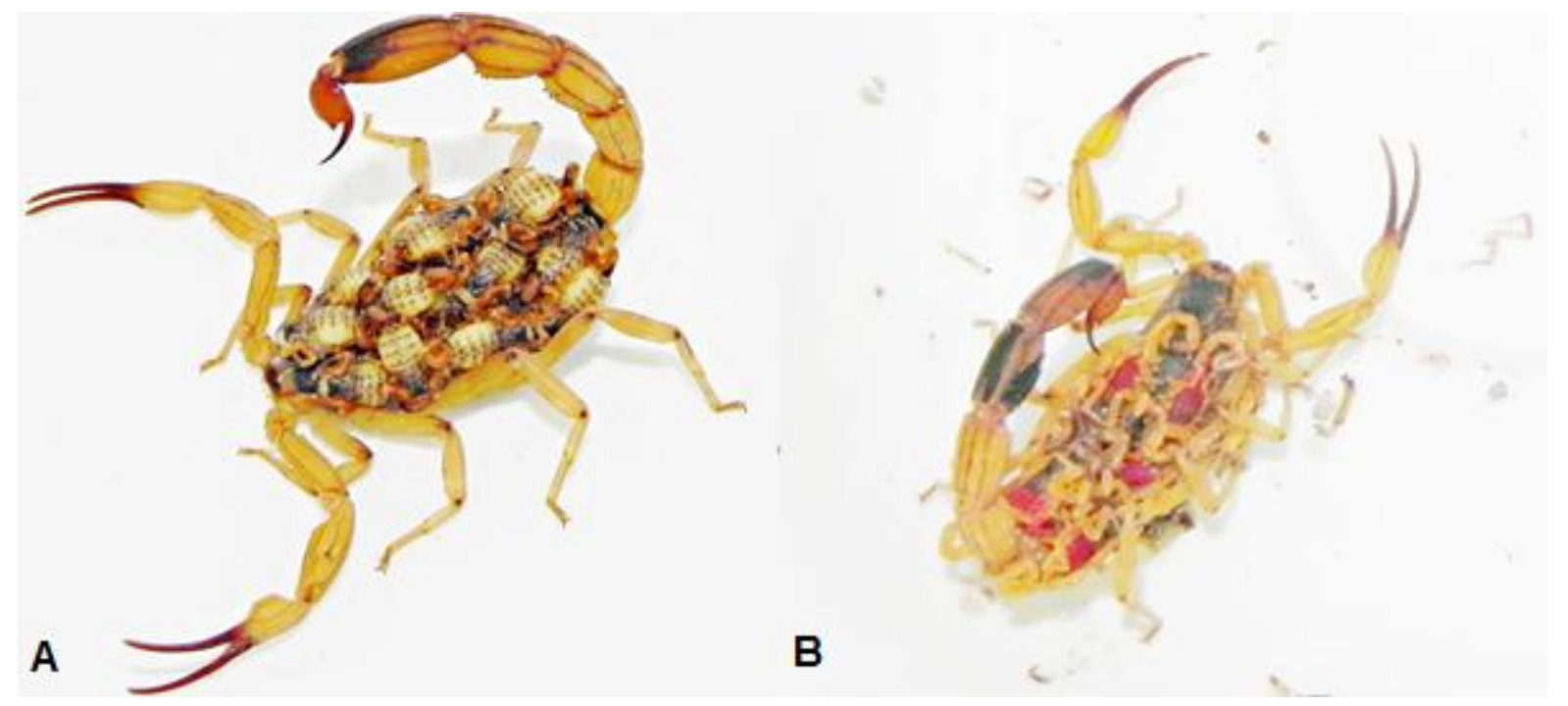

Figura 3. Filhotes no dorso da fêmea. (A) Prole de primeiro ínstar, (B) prole de segundo ínstar com indivíduos marcados com tinta vermelha. 
Em Tityus serrulatus o gregarismo ocorre, e sabe-se a que a espécie apresenta pouca movimentação quando observada nestas circunstâncias, comportamento influenciado provavelmente pelo tipo de estratégia de caça, classificada como "senta e espera" (Polis \& Farley, 1979; Mineo et al., 2003; Colombo \& Alencar, 2013). Outro aspecto relacionado ao comportamento e a reprodução nos escorpiões é o aborto e o canibalismo materno, onde a fêmea se alimenta de indivíduos recém nascidos ou natimortos (Polis \& Farley, 1980; Polis \& Sissom; 1990; Outeda-Jorge, 2009). Por ser um animal extremamente adaptado a ambientes urbanos e com ausência de predadores naturais nestes locais, o comportamento de agregação pode estar relacionado às circunstâncias ambientais conforme relatado anteriormente, e parece aumentar a densidade populacional desta espécie, o que pode ser um dos fatores determinantes para o sucesso adaptativo deste escorpião. 
Objetivos

O presente estudo visa avaliar a influência da densidade na fertilidade dos indivíduos de Tityus serrulatus em diferentes níveis. Os objetivos específicos são:

1. Analisar o número de filhotes gerados em diferentes densidades de fêmeas de escorpiões.

2. Comparar as ninhadas observando a relação entre a quantidade de filhotes o peso e o tamanho destes com o tamanho e peso dos adultos.

3. Analisar os efeitos da densidade na taxa de mortalidade dos escorpiões adultos.

\section{Hipótese}

Existe diferença entre o número de descendentes de indivíduos sujeitos a densidades variáveis, desde isolados até altas densidades. 


\section{MATERIAL E MÉTODOS}

\section{Coleta dos escorpiões}

Os adultos de Tityus serrulatus foram coletados principalmente em bueiros de águas pluviais, esgotos, caixas subterrâneas de energia elétrica e de telefone e em entulhos de construções civis, na Universidade de Brasília (Campus Darcy Ribeiro) na Asa Norte, em uma área que abrange o Instituto de Ciências Biológicas a Faculdade de Medicina e os Correios. Em Taguatinga Norte (Distrito Federal) a coleta foi realizada entre as quadras 6 e 13 da Avenida SAMDU. Para auxiliar nas coletas foi utilizada uma lanterna tática da marca JWS (WS-977) com LED branco e LED ultra violeta, a luz UV facilita a visualização dos escorpiões, uma vez que estes absorvem esta luz (comprimento de onda entre 350-400 nm) e a refletem na cor verde ciano (Gaffin et al., 2012), facilitando assim sua visualização aos olhos humanos. Outro objeto utilizado foi uma pinça longa $(20 \mathrm{~cm})$ para uma captura segura e eficiente.

\section{Manutenção em laboratório}

Os indivíduos coletados foram mantidos em potes individuais por sete dias. Após o período de isolamento cada escorpião foi destinado a um tratamento do experimento. Eventos reprodutivos ocorridos nos dois primeiros meses não foram considerados. Os animais que morreram nos grupos de tratamento foram substituídos, de forma a manter o mesmo número de indivíduos.

O escorpiões foram colocados em potes plásticos brancos (tipo de sorvete) com $15 \mathrm{x}$ 13 x $13 \mathrm{~cm}$, tampas com cinco furos (um em cada canto e um central) de $3 \mathrm{~mm}$ de diâmetro, com substrato de tijolo e um pequeno recipiente de $1,5 \mathrm{~cm}$ de diâmetro com algodão umedecido (Fig.1). Os potes foram armazenados em estante escura e mantidos em temperatura e umidade ambientes.

\section{Experimento}

Três tratamentos foram utilizados para a realização do experimento (Fig. 4), com início em agosto de 2015 e término em novembro de 2016. 
Os três tratamentos foram: (1) o controle (C), foi de um indivíduo por pote, totalizando 16 escorpiões, sendo 0,005 escorpiões por $\mathrm{cm}^{2}$ a densidade; (2) grupo 1 (G1), com três indivíduos por pote, totalizando 13 potes, 39 indivíduos e densidade 0,015; e (3) o grupo 2 (G2) com seis indivíduos por potes, totalizando 11 potes, 97 indivíduos e com densidade 0,030 .
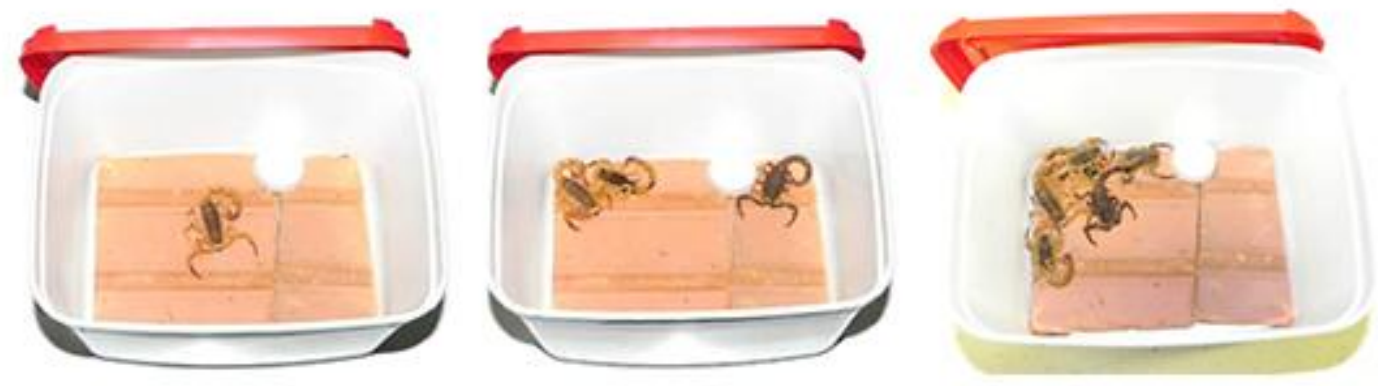

Figura 4. Potes contendo a distribuição de animais por forma de tratamento, onde é possível visualizar o controle, Grupo 1 e Grupo 2, respectivamente.

As fêmeas foram pesadas quinzenalmente em uma balança eletrônica analítica de alta precisão $(0,001 \mathrm{~g})$ da marca "Marte" modelo AL500. As pesagens ocorreram antes das refeições e 24 horas após as mesmas. As fêmeas também foram pesadas assim que observada ocorrência dos eventos reprodutivos, onde foram registrados os pesos com os filhotes em seu dorso e sem os filhotes, assim como todos os filhotes oriundos de cada evento reprodutivo foram pesados de forma indivídual.

O tamanho das fêmeas e filhotes considerou o comprimento desde a borda anterior do prossoma (antes das quelíceras) até o final do penúltimo segmento do mesossoma (Fig. 5). Esta padronização foi necessária devido ao fato de que o metassoma ("cauda"), em animais vivos, ficar curvado quando em posição defensiva, dificultando a medição. Os indivíduos foram fotografados sobre papel milimetrado com uma câmera Nikon P100, e posteriormente o tamanho foi mensurado utilizando-se o programa Snake-Measure Tool. Este procedimento foi realizado logo o nascimento dos filhotes.

A alimentação dos escorpiões foi baseada em baratas adultas da espécie Leurolestes circunvagans (quinzenalmente), de acordo com o número de indivíduos por tratamento, onde, no controle foi disponibilizada uma barata, no G1 três baratas e para o G2 seis baratas (sempre ficando disponível no pote uma barata para cada escorpião); após $24 \mathrm{~h}$, as presas 
foram retiradas (as não consumidas, e os restos das presas consumidas), a água foi disponibilizada “ad libitum”, sempre que necessário para umidificar o cativeiro.

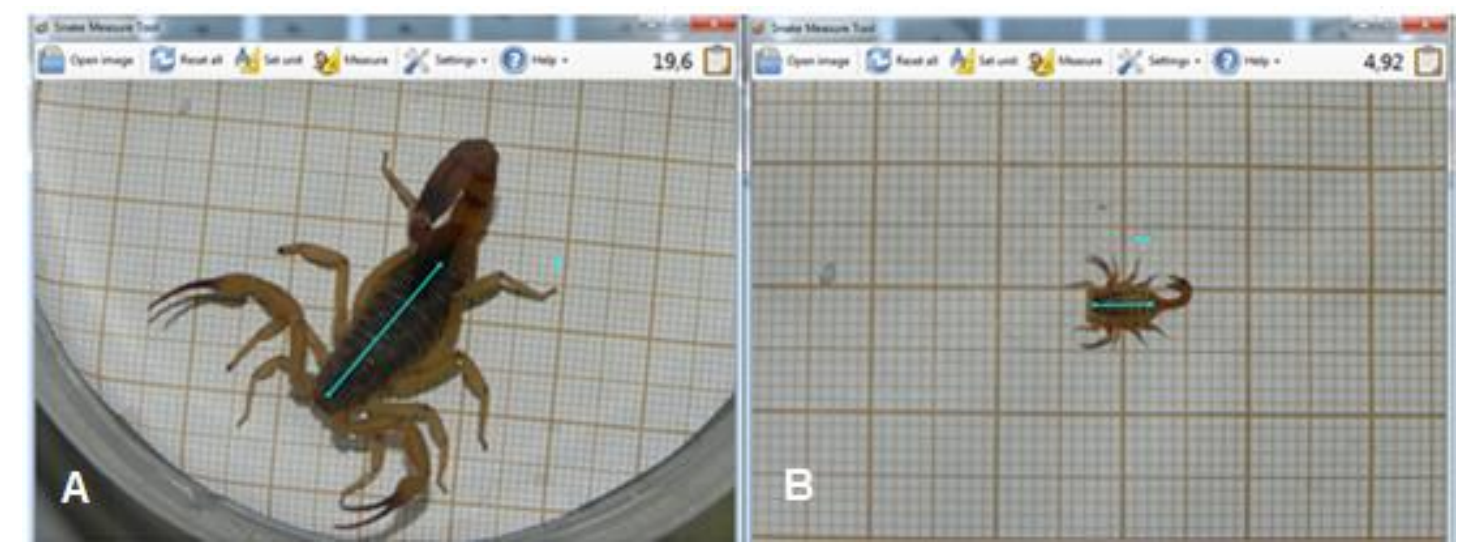

Figura 5. (A) Adulto, (B) filhote do primeiro ínstar tendo o tamanho mensurado através do programa Snake Measure tool.

\section{Sistema de marcação}

Para o acompanhamento individual dos escorpiões dos grupos G1 e G2, estes foram identificados com "marcador para quadro branco", da marca "Pilot" e com tinta do tipo WBS-VBM, solúvel em água e resistente a mesma após aplicação. A marcação (Fig. 6) iniciava no último segmento do mesossoma, indicando o número 1 , e terminava no último segmento do metassoma (número 6).
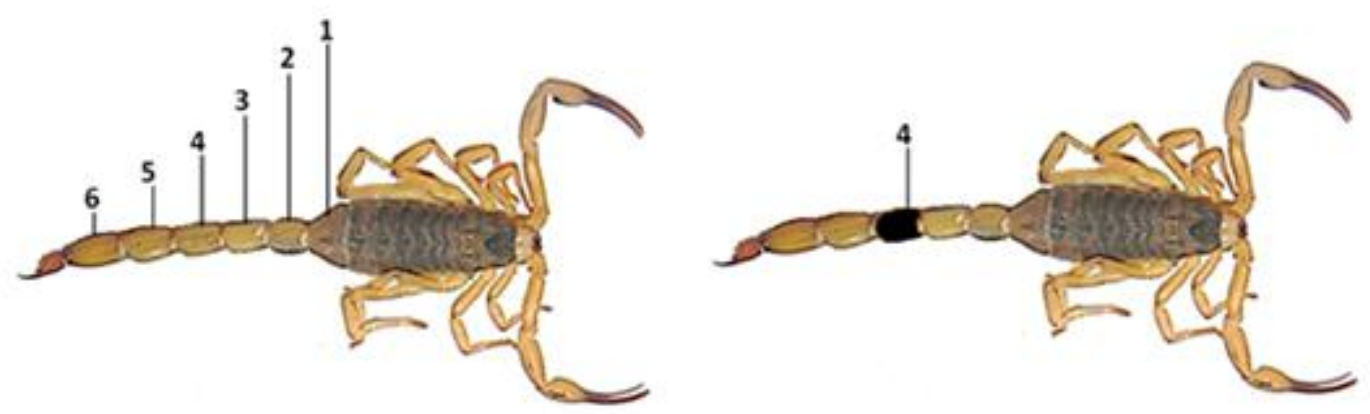

Figura 6. Exemplo do sistema de marcação utilizado no experimento e indivíduo marcado, respectivamente.

\section{Análise dos dados}


Para analisar a diferença do número de eventos reprodutivos entre os tratamentos foi utilizado o teste não-paramétrico de Kruskal-Wallis. Para analisar a diferença quantitativa de filhotes em detrimento da densidade e por peso da fêmea foi feito um modelo misto, onde a variável aleatória foi a identificação da fêmea. Foi calculada também a correlação entre variáveis de qualidade das fêmeas e de suas proles. Esta análise foi feita com um modelo aninhado, onde a identificação da fêmea estava aninhada dentro do número de filhotes da prole. O tamanho e peso das fêmeas não foram incluídos juntos no mesmo modelo, já que as duas variáveis estavam fortemente correlacionadas. A análise referente à oferta $\mathrm{X}$ consumo de presas entre eventos reprodutivos foi feita através de um modelo aninhado, tendo como variável resposta a porcentagem de presas consumidas e prole estando aninhada dentro de tratamento, sendo a identidade do pote um fator aleatório. O “ $\beta$ ” observado nas análises corresponde a estimativa da correlação entre as variáveis, onde positivo significa reta ascendente e negativo descendente. Estas análises foram feitas com utilização do programa R, versão 3.2.4. As análises referentes a significância da fertilidade das fêmeas por tratamento e a mortalidade por grau de tratamento foram calculadas através do teste Qui-quadrado com o uso do software Statistica, versão 8.0. 


\section{RESULTADOS}

\section{Eventos reprodutivos e fertilidade}

Foram usados no experimento 153 escorpiões, coletados entre maio de 2015 até agosto de 2016, ao todo foram feitas 51 reposições devido a óbitos.

Durante o experimento nasceram 1.642 filhotes, oriundos de 125 eventos reprodutivos (Fig. 7). Os escorpiões reproduziram durante todo o ano, sendo outubro o mês com maior número de partos, tanto no ano de 2015 quanto no ano de 2016, bem como a quantidade de filhotes nascidos, onde 556 filhotes nasceram em 2015 e 264 em 2016, o que correspondeu a $49,9 \%$ do total de filhotes nascidos no experimento.

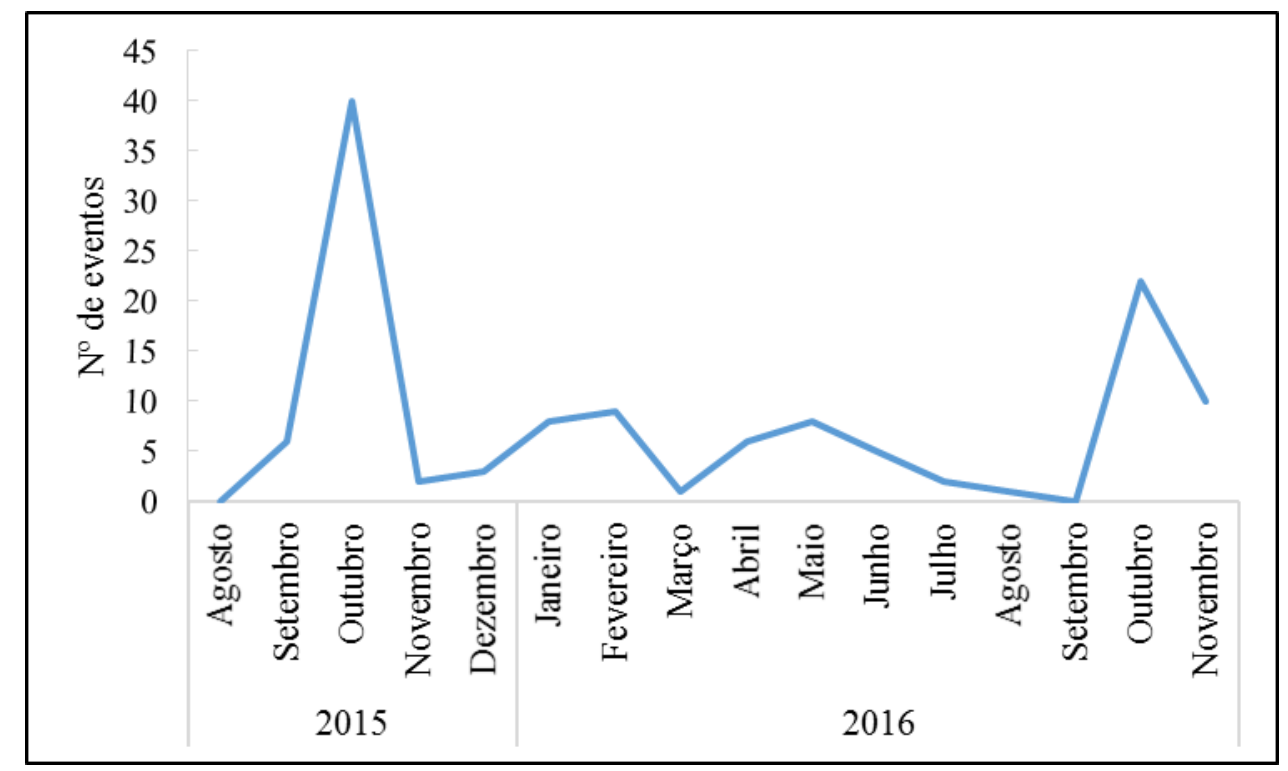

Figura 7. Total de eventos reprodutivos ocorridos entre agosto de 2015 a novembro de 2016.

O número médio de eventos reprodutivos diminuiu com o aumento da densidade (Fig. 8), onde o controle apresentou 1,46, o G1 foi 1,3 e o G2 1,1 (Kruskal-Wallis demonstrou que $\chi^{2}=7,444$ e $\mathrm{p}=0,0242$ ). No controle $88 \%$ das fêmeas reproduziram, no G1 87,5\%, e no G2 a taxa reprodutiva foi de $55,7 \%$. A densidade influenciou na fertilidade das fêmeas $\left(\chi^{2}=11,523\right.$ $\mathrm{e} p=0,0006)$. 


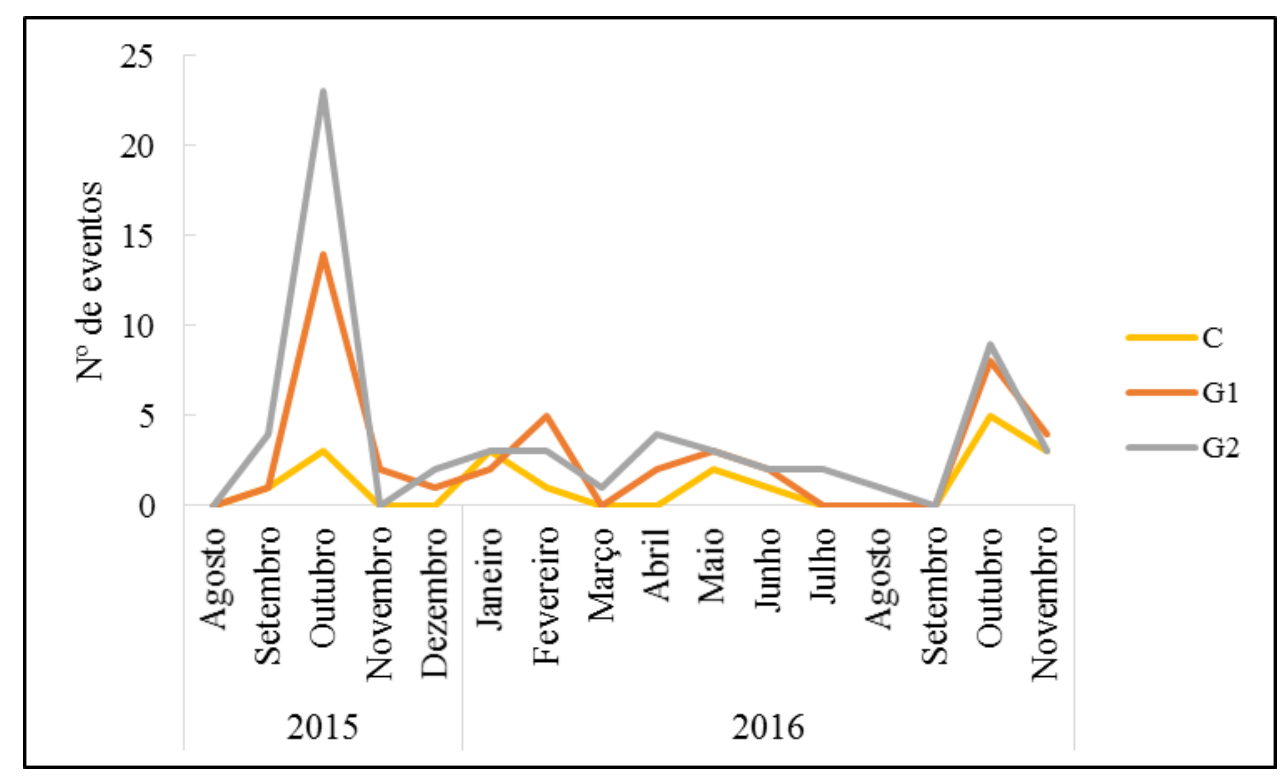

Figura 8. Número de eventos reprodutivos por tratamento, entre agosto de 2015 e novembro de 2016.

Tabela 1. Número de partos por tratamento. NTF, número total de fêmeas; DNS, densidade por $\mathrm{cm}^{2}$; NFR, número de fêmeas que reproduziram; NER, número de eventos reprodutivos e FR, fêmeas com mais de uma reprodução.

\begin{tabular}{|c|c|c|c|c|c|}
\hline Tratamento & NTF & DNS & $\operatorname{NFR}(\%)$ & $\operatorname{NER}(\%)$ & FR (\%) \\
\hline $\mathrm{C}$ & 16 & 0,005 & $14(0,87)$ & $20(1,25)$ & $4 \quad(0,25)$ \\
\hline G1 & 40 & 0,015 & $35(0,87)$ & $45(1,25)$ & $10(0,25)$ \\
\hline $\mathrm{G} 2$ & 97 & 0,030 & $54(0,55)$ & $60(0,61)$ & $5 \quad(0,05)$ \\
\hline Total & 153 & ----- & 97 & 125 & 19 \\
\hline
\end{tabular}

Das fêmeas que reproduziram mais de uma vez, 19 delas chegaram a dois eventos reprodutivos e apenas três destas chegaram ao terceiro evento reprodutivo (este desconsiderado para análise devido ao tamanho da amostra), sendo uma do G2 e duas do controle. Foram ofertadas 430 baratas para estes indivíduos, e a média de consumo por escorpião foi de 2,7 baratas entre os partos. A relação oferta $X$ consumo de presas entre eventos reprodutivos destes animais foi analisada, e o percentual de presas consumidas não foi influenciado pela densidade entre os tratamentos (Controle $X \mathrm{G} 1, \beta=0,0750, p=0,6892$; 
Controle X G2, $\beta=0,1911, p=0,3740$ e nem entre as ninhadas, Controle ninhada A X Controle ninhada $B, \beta=0,0812, p=0,7173$; $G 1$ ninhada $A X$ G1 ninhada $B, \beta=-0,0888, p=0,5311$; e G2 ninhada A X G2 ninhada $B, \beta=-0,0648 ; p=0,7453)$.

\section{Tamanho da prole e correlações entre adultos e ninhadas}

A média de filhotes gerados por fêmea foi de 17,9 no grupo controle, 15,7 no G1 e 15,9 no G2; não houve efeito da densidade na quantidade de filhotes $(\beta=-2,486 ; p=0,1375$ e G2, $\beta=2,529$ e $p=0,1129$ ) e nem no peso dos filhotes (G1 $\beta=0,0017 ; p=0,1457$ e $\beta \mathrm{G} 2=-0,0002 ; \mathrm{p}=0,8518$ ), não havendo também correlação entre o peso do adulto e a quantidade de filhotes $(\beta=-2,831$ e $p=0,2837)$ mas, existindo correlação positiva entre o peso dos adultos e o peso dos filhotes $(\beta=0,0064 ; \mathrm{p}=0,0017)$. Os tamanhos mínimos e máximos das proles foram: Controle (6 e 25), grupo 1 ( 3 e 24 ) e grupo 2 ( 2 e 32 ).

\section{Mortalidade}

A mortalidade aumentou conforme o grau de agregação: animais isolados (controle) apresentaram 25\% de óbitos (4), no G1 cerca de 55\% (22) e no G2, 73,2\% (69), demonstrando que houve efeito do tratamento no número de óbitos $\left(\chi^{2}=217,2673 ; p=0,0001\right)$.

\section{Canibalismo}

Durante o experimento ocorreram dois casos de canibalismo, ambos no dia da alimentação e no Grupo 2, entretanto em potes diferentes. Um dos casos envolveu indivíduos adultos, onde, após a reposição de um escorpião e decorridas as 24 horas da alimentação, constatou-se que o animal recém introduzido havia sido morto e teve o cefalotórax e pré-abdômen consumidos por alguns indivíduos do recinto, restando apenas algumas das partes mais esclerotizadas (Fig. 9). O outro registro é referente ao canibalismo materno, onde foi possível observar a fêmea com o filhote recém-nascido em suas quelíceras (Fig. 10) e o consumo deste após certo tempo. 


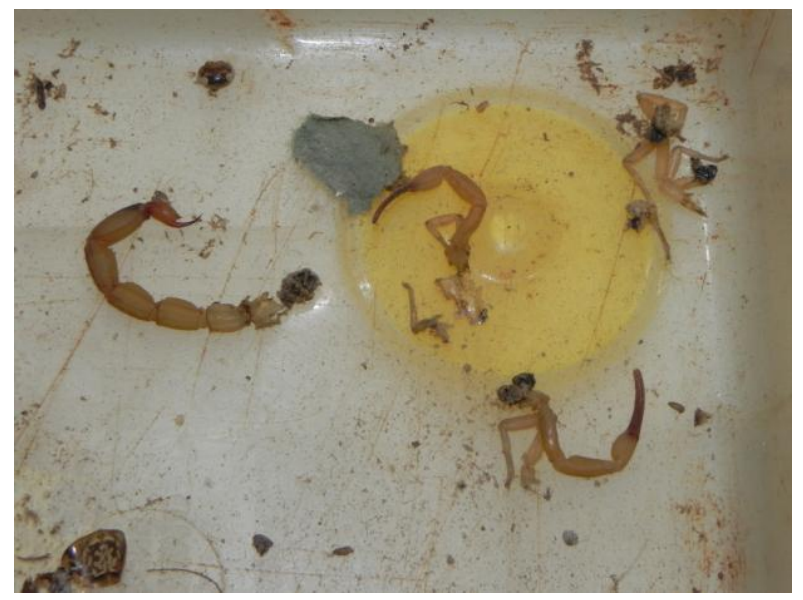

Figura 9. Indivíduo predado logo após ser inserido no grupo 2.

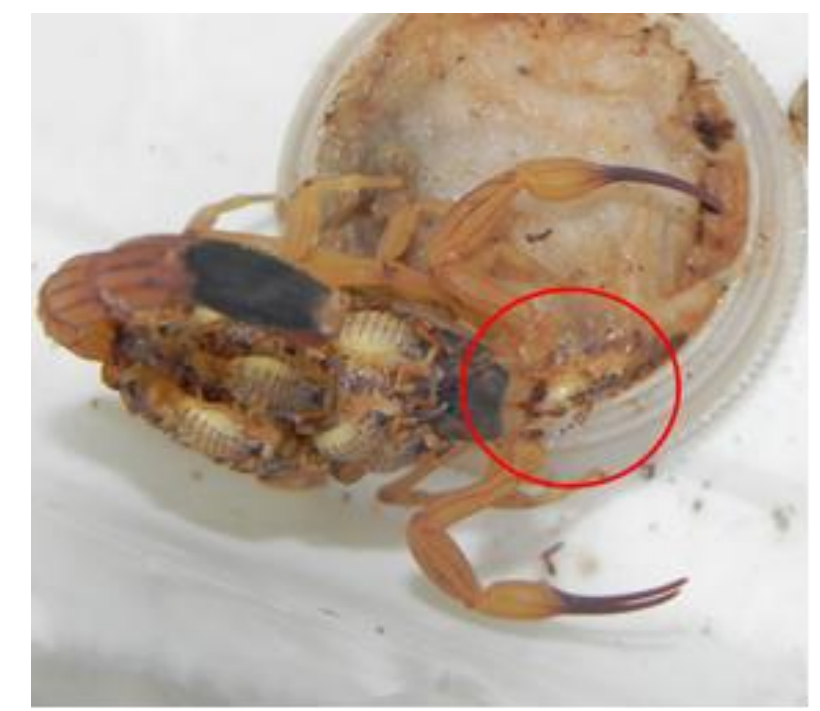

Figura 10. Adulto de Tityus serrulatus predando filhote recém-nascido.

\section{Aborto/Natimorto}

No dia 15 de março de 2016 observou-se no recinto do escorpião C6 cerca de dez indivíduos abortados, de diferentes tamanhos e estágios de formação (Fig. 11). Em 27 de abril de 2016 uma das fêmeas do G2 deu à luz a seis natimortos (Fig. 12), não sendo possível verificar a ocorrência de canibalismo antes ou após este parto. 


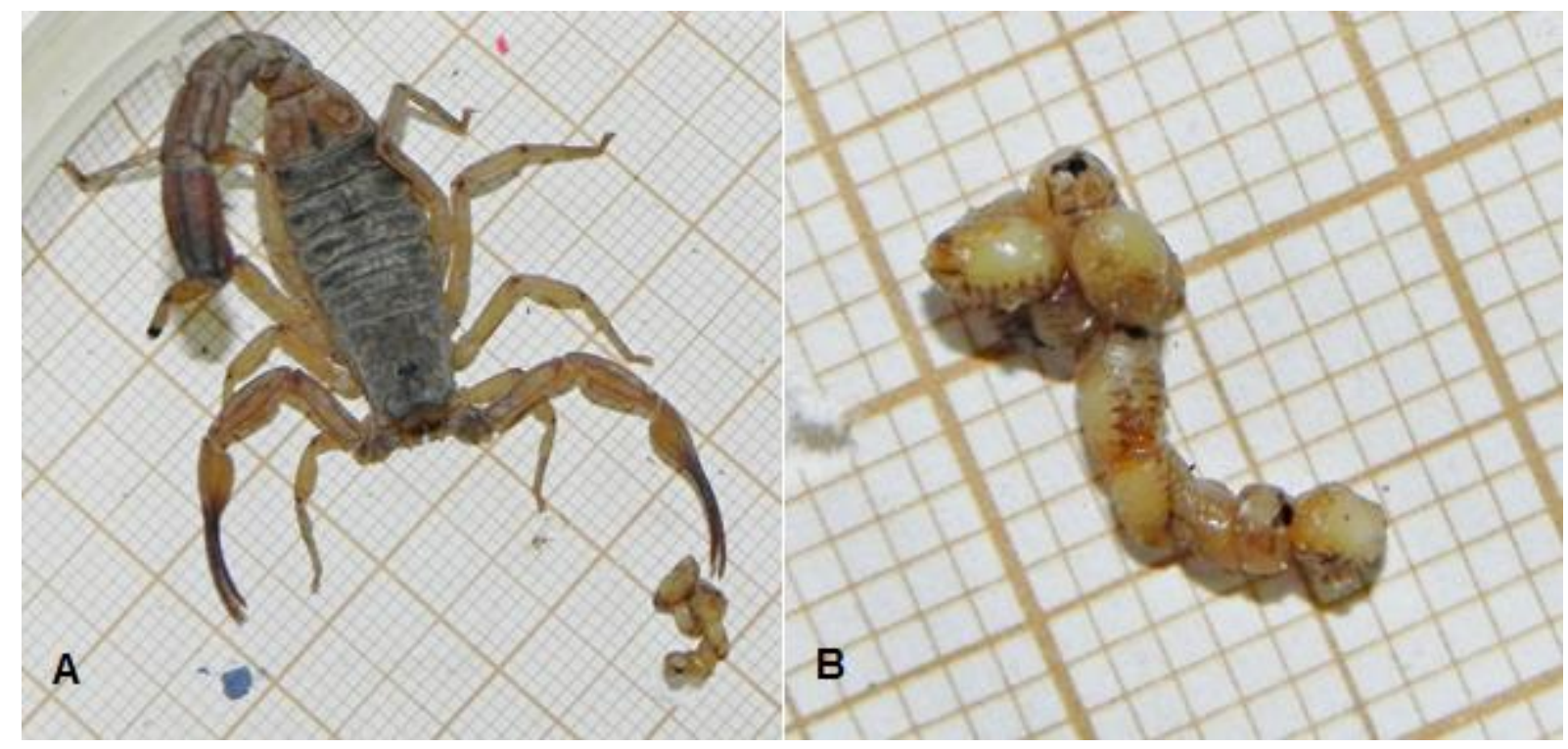

Figura 11. (A) Indivíduo C6 do controle com sua prole recém abortada, (B) ampliação para melhor visualização dos diferentes estágios de formação.

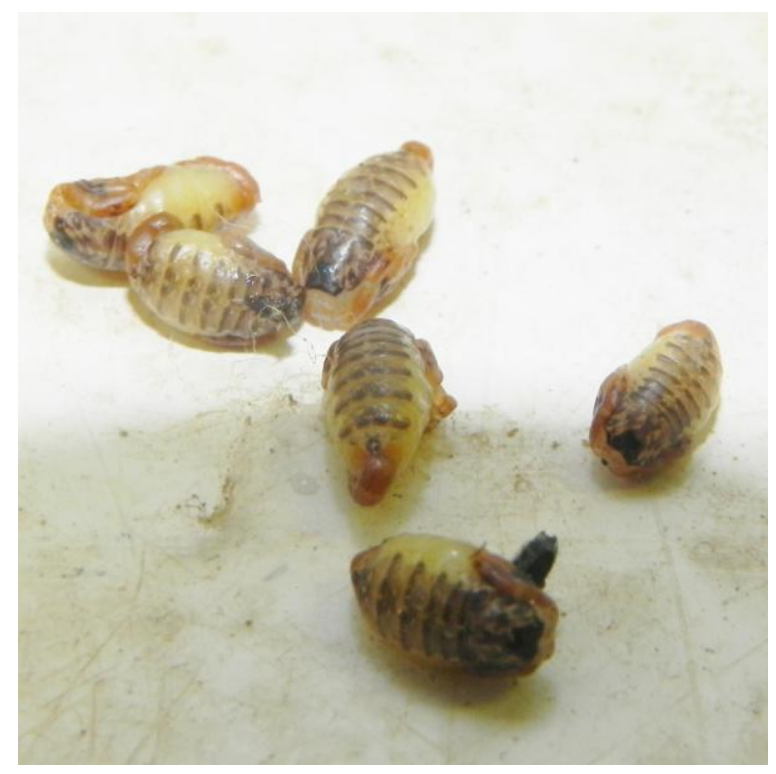

Figura 12. Filhotes natimortos do Grupo 2.

\section{Compartilhamento de prole}

Foram observados casos onde alguns filhotes saíram de suas mães e deslocaram-se para o dorso de outras fêmeas. Este "compartilhamento" de prole ocorreu uma vez no G1 e oito vezes no G2. Em um dos casos os filhotes de um ínstar mais avançado foram para o dorso de uma fêmea (Fig. 13) que tinha seus filhotes (ínstar I) no dorso. Nas demais 
ocorrências os filhotes estavam no primeiro ínstar. As fêmeas que protagonizaram estas ocorrências demonstraram boa aceitação da prole "invasora".
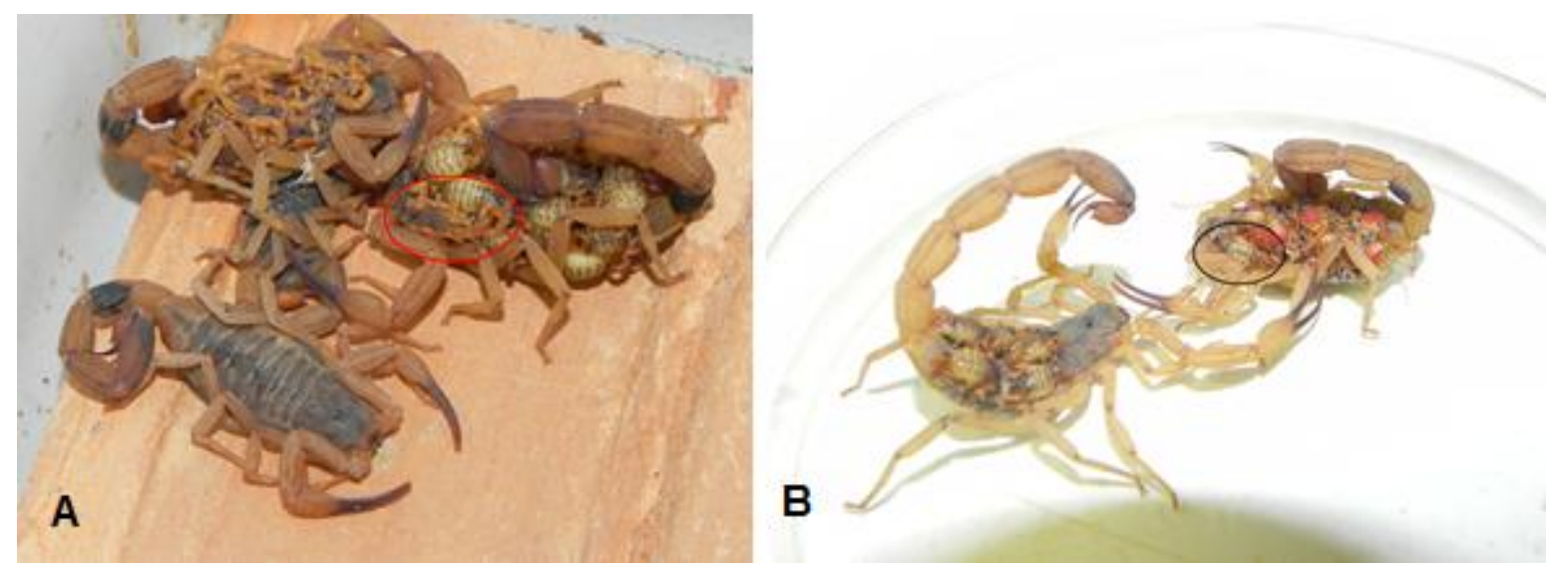

Figura 13. (A) Filhote do ínstar II em uma fêmea com prole recém nascida. (B) filhote sem marcação junto a prole de outra fêmea. 


\section{DISCUSSÃO}

\section{Eventos reprodutivos e fertilidade}

Os eventos reprodutivos foram dependentes da densidade, onde quanto menor o número de indivíduos em determinado ambiente, maior o número de partos. Este efeito pode ser explicado pela existência da competição intraespecífica dos organismos, podendo ser visto tanto na fecundidade, mortalidade ou na combinação dos dois (Begon, 2006), o que foi observado neste estudo. A combinação entre mortalidade e densidade ocasionou a diminuição do tempo de vida dos indivíduos, refletindo assim no número de eventos reprodutivos, acentuando esta dependência negativa da densidade.

É possível observar que no início do experimento os grupos com maior número de indivíduos (G1 e G2) ainda não sofriam possíveis efeitos da densidade, em relação ao número de eventos reprodutivos. Com o passar do tempo estes foram demonstrando uma diminuição do número de partos. No G1 e G2 ocorreram picos reprodutivos bem marcantes em outubro (2015/2016), e picos menores entre janeiro e fevereiro e abril e maio (2016). O controle apresentou um padrão mais uniforme, onde os picos (outubro, janeiro e maio) tiveram números semelhantes.

A distribuição do número de eventos reprodutivos encontradas no G1 e G2 diferiram no aspecto quantitativo em relação ao controle, entretanto, a distribuição ao longo do ano foi semelhante, onde os escorpiões dos três tratamentos reproduziram durante todo o ano, fato já descrito para esta espécie (Lourenço \& Cuellar, 1995; Eickstedt et al., 1996; Knox, 1997; Outeda-Jorge, 2009). O fato de ocorrerem nascimentos durante todo o período reforça o potencial colonizador de Tityus serrulatus e sua estratégia reprodutiva (Lourenço, 1991). O padrão observado no controle, provavelmente retrata a realidade da espécie no ambiente "natural” e sua independência da densidade (Lourenço et al., 1994; Knox, 1997).

Entretanto, a diferença do número de eventos reprodutivos de G1 e G2 em comparação com o controle, induz ao pensamento que por mais que Tityus serrulatus seja uma espécie invasora, resistente aos fatores ambientais e possua alta plasticidade (Lourenço, 1994; Knox, 1997), quando submetida a uma grande densidade de indivíduos em um ambiente limitado (quanto a área), este acaba sofrendo os aspectos negativos de se viver em locais muito populosos e com um agregado além da capacidade ambiental (Hamilton, 1971; Wilson 1975; Rypstra, 1985). 
Dezenove escorpiões realizaram mais de um evento reprodutivo, e três destes tiveram um terceiro parto, padrão também observado por Matthiesen (1971), Lourenço (2000) e Outeda-Jorge (2009), onde viu-se que esta espécie tem capacidade de ter até mais de uma reprodução por ano.

A época reprodutiva mais intensa foi em outubro para os tratamentos do G1 e G2, e para o controle, conforme relatado anteriormente, em janeiro, maio e outubro. Estes dados diferem dos observados por Outeda-Jorge (2009), onde os eventos ocorreram entre fevereiro a abril e em dezembro, meses os quais também observamos eventos reprodutivos, porém com menor intensidade. Uma explicação possível para a observação de um "pico" reprodutivo talvez seja justificada pela diferença do tamanho da amostra, uma vez que nossa amostra foi aproximadamente nove vezes maior $(97$ - 11) do que a do estudo citado anteriormente. Alternativamente, tal desigualdade pode ser justificada pela eventual diferença sazonal entre Brasília e a cidade de São Paulo. O padrão reprodutivo de aracnídeos de solo do Cerrado, ocasiona picos em outubro, época na qual os machos saem em busca das fêmeas para a realização de cópulas (Motta, 2014).

O pico reprodutivo em outubro acompanha parcialmente o aumento de acidentes ocorridos no Distrito Federal (setembro, outubro e novembro). Segundo os órgãos competentes, estes meses tem maior número de acidentes devido a chegada da estação chuvosa, pois estes animais acabam fugindo das instalações de águas pluviais devido ao grande volume de água.

Foi analisado o consumo de presas dos escorpiões que chegaram a mais de um evento reprodutivo, a fim de observar a existência de correlação entre a densidade e o consumo no pré e pós parto das ninhadas. Os resultados demonstraram que neste caso a densidade não teve efeito significativo, e aparentemente o consumo mostrou-se baixo, algo normal em escorpiões (Polis, 1990). Estes animais apresentam uma das mais baixas taxas metabólicas, sendo isto possível graças a pouca movimentação e a estratégia de caça do tipo senta e espera, o que lhe permite uma grande conversão de biomassa da presa. Outra informação importante para compreender este baixo consumo deve-se ao fato do investimento reprodutivo (perda de peso do adulto antes e após eventos reprodutivos) de Tityus serrulatus ser pequeno, onde Knox (1997) demonstrou que o investimento da espécie é baixo comparado a uma outra espécie que apresenta apenas reprodução sexuada (Tityus fasciolatus Pessoa, 1935), e que isto pode lhe conceder vantagens colonizadoras e dispersivas. Para reforçar esta relação do esforço 
reprodutivo em Tityus serrulatus neste estudo, seria interessante realizar análises referentes a esta questão.

\section{Tamanho da prole e correlações entre adultos e ninhadas}

O tamanho médio da prole foi de 16,5 indivíduos, variando de dois a 32. A média está dentro das observadas por outros autores que é de 14 e 21 filhotes (Matthiesen, 1971; Knox, 1997; Outeda-Jorge, 2009). Estas divergências podem estar relacionadas ao tamanho das amostras de cada trabalho, bem como pelas especificidades de cada experimento.

A densidade não teve efeito significativo no número médio de descendentes por evento reprodutivo. A alimentação foi padronizada e o consumo de presas pelos escorpiões mostrou-se baixa aparentemente. A densidade também não influenciou no peso dos filhotes, o que novamente pode estar correlacionado com a questão de aquisição energética e o esforço reprodutivo, sendo necessária uma melhor investigação deste aspecto. Alguns estudos com passeriformes (Parus major Linnaeus, 1758) apontam que a densidade tem a capacidade de influenciar no tamanho da ninhada, onde um menor número de adultos por área costuma resultar em um aumento na quantidade de filhotes por ninhada (Both \& Visser, 2000), entretanto a disponibilidade de alimento pode "anular" este efeito da densidade.

As análises de correlação entre adultos e suas ninhadas demonstraram que o peso do adulto não exerceu influência na quantidade de descendentes nascidos, padrão também observado por Knox (1997) para T. serrulatus. Em aranhas e escorpiões tem-se o conhecimento que geralmente fêmeas maiores dão luz a proles mais numerosas e os filhotes destas também são maiores (Enders, 1976; Brown 2003, 2004). Entretanto não é regra para todas as espécies e nem mesmo para populações dentro da mesma espécie, como é o caso da espécie alvo deste trabalho. Esta não correlação entre o tamanho do adulto e o tamanho da ninhada também foi observado por Knox (1997) e Outeda-Jorge (2009), mas o peso do adulto apresentou correlação positiva com o peso dos filhotes. Killebrew \& Ford (1985) observaram correlação positiva entre o peso da aranha Peucetia viridans Hentz, 1832 e o peso dos filhotes, e Brown (2004) também relatou correlação positiva entre o tamanho da fêmea com o tamanho dos filhotes para escorpiões. 


\section{Mortalidade}

Inúmeros patógenos foram descritos como causadores de doenças em escorpiões na natureza, tais como bactérias, fungos e vírus (Matthiesen, 1984; Santana-Neto et al., 2010). Também foram relatados nematoides (Gouge \& Snyder, 2005) como responsáveis por mortes para este grupo. O fato de Tityus serrulatus ser encontrado agregado no ambiente em que se estabeleceu, potencializa possíveis prejuízos ao ciclo de vida destes animais, entre eles o aumento da mortalidade, uma vez que a agregação intensifica a probabilidade de doenças e transmissão de parasitas (Wilson, 1971, 1975; Alexander, 1974; Anderson, 1984; Pullian \& Caraco, 1984). Assim, o aumento da mortalidade em função da densidade neste estudo pode ter sido causado por alguns dos fatores acima citados, tendo também como possível causa o aumento do estresse devido ao tamanho do espaço existente.

\section{Canibalismo}

O canibalismo em escorpiões não é incomum, embora não ocorra com tanta frequência e nem seja regra para todas as espécies (Polis \& Farley, 1979; Polis, 1990; Shivashankar, 1994). Durante todo o experimento tivemos apenas uma ocorrência envolvendo indivíduos adultos, e assim mesmo com um animal recém introduzido em um grupo de alta densidade. Observamos também um único caso de canibalismo materno, ocorrido neste mesmo tratamento, o G2. O canibalismo de indivíduos adultos e de filhotes é citado como algo fortemente relacionado aos estresses ambientais aos quais os indivíduos são submetidos, entre eles a falta de recurso alimentar (Polis \& Farley, 1980; Polis \& Sissom; 1990; Bilde \& Lubin, 2001; Outeda-Jorge, 2009). A chance destes acontecimentos estarem ligados a alta densidade de indivíduos em um pequeno espaço neste experimento é real, visto que os dois casos ocorreram nos tratamentos de maior densidade e a alimentação era padronizada. Entretanto, faz-se necessário uma melhor investigação, potencializando a amostra para que fique mais claro este tipo de comportamento em T. serrulatus.

\section{Aborto/Natimorto}

Foram observados abortos em dois indivíduos presentes em tratamentos com densidades diferentes (C e G2). Como estas ocorrências foram limitadas não foi possível 
realizar nenhuma análise para correlacionar este acontecimento a densidade ou a qualquer outro tipo de fator, embora tenha sido relatado estresses referentes ao cativeiro como possíveis causas (Polis \& Sissom, 1990). Este tipo de registro já havia sido descrito para outras espécies, tais como Rhopalurus agamemnon Koch, 1839, Bothriurus araguayae Vellard, 1934, Bothriurus rochensis San Martin, 1965, Rhopalurus rochai Borelli, 1910 e Tityus bahiensis Perty, 1883 (Outeda-Jorge, 2009). Para Tityus serrulatus trata-se dos primeiros registros relatados oficialmente. Vale ressaltar que o ocorrido demonstra a perda de filhotes em duas fases distintas do desenvolvimento, uma fase mais inicial, onde é possível observar formação incompleta do que seriam os filhotes e em um estágio mais avançado, onde os indivíduos já possuíam uma aparência escorpiônica, porém ainda assim não obtiveram sucesso ao deixar o corpo da mãe.

\section{Compartilhamento de prole}

Kullman (1972) relatou que a tolerância recíproca é provavelmente o primeiro passo para a evolução da socialidade. A tolerância em escorpiões é conhecida para algumas espécies, entre elas o e Opisthacanthus cayaporum, escorpião da região amazônica, que vive em cupinzeiros e pode ser encontrado em "grupos" com até quinze indivíduos, demonstrando um certo nível de tolerância com outros escorpiões da mesma espécie. Alguns escorpiões como o Pandinus imperator e o Heterometrus fulvipes (Mahsberg, 1990; Shivashankar, 1994) além de tolerarem indivíduos semelhantes, apresentam cuidado parental com suas proles e até mesmo com proles "vizinhas". Sabe-se que no caso de Heterometrus fulvipes ocorre alimentação compartilhada entre filhotes e adultos de diferentes "famílias", e em Pandinus imperator ocorre tolerância de adultos com filhotes de outros indivíduos. Estes relatos citam filhotes a partir do segundo ínstar, fase em que eles estão mais dispersos, porém, em ambas as espécies os mesmos tendem a ficar próximos dos adultos. A presença dos adultos aumenta consideravelmente a sobrevivência dos filhotes, seja através de alimentação, proteção ou abrigo. Stegodyphus lineatus Latreille, 1817 foi o primeiro caso descrito de indivíduos subsociais para aranhas com comportamento diferenciado com parentes, o que influenciou em uma maior permanência e tolerância destes indivíduos (Bilde \& Lubin, 2001). Outras espécies de aranhas também demonstram tolerância com parentes e até mesmo indivíduos não relacionados com seus grupos (Kullmann, 1972; Brach 1977; Darchen \& Delage-Darchen, 1986; Pasquet et al., 1997). Em Tityus serrulatus existe um registro de alimentação dos 
filhotes (Colombo \& Alencar, 2013), entretanto ainda não se tinha registros de tolerância com filhotes de outros indivíduos, o que foi possível observar neste trabalho. Algumas fêmeas toleraram filhotes tanto do primeiro ínstar como do segundo ínstar em seu dorso, bem como os filhotes que ali estavam também toleraram a presença do "invasor", não sendo observado agressão entre eles.

O reconhecimento de parentes é importante para uma possível transição entre níveis de socialidade, uma vez que tende a aumentar a tolerância entre os indivíduos (Kullmann, 1972). Este comportamento em Tityus serrulatus pode ser benéfico para os filhotes pela questão de sobrevivência, e para os adultos pelo fitness inclusivo, uma vez que por se tratar de uma população partenogenética no DF, a similaridade genética dos indivíduos pode ser alta, o que pode potencializar aspectos relacionados ao reconhecimento e aceitação de parentes. Entretanto, faz-se necessário uma investigação mais profunda destes registros, procurar entender seu funcionamento, estrutura, motivação e reais benefícios. 


\section{CONCLUSÃO}

O presente estudo demonstrou que Tityus serrulatus de fato é uma espécie com alta capacidade reprodutiva, apresentando eventos reprodutivos ao longo de todo o ano, mas com pico em outubro, início da estação chuvosa no Distrito Federal. A densidade influenciou neste aspecto reprodutivo do escorpião amarelo, onde indivíduos vivendo em maiores agregações tiveram o número de eventos reprodutivos afetado pela densidade. Este resultado aparenta ter correlação com a taxa de mortalidade dependente da densidade, onde, com a redução do tempo de vida dos indivíduos (em cativeiro), estes passam a ter menos oportunidades reprodutivas ao longo de seus ciclos. Por outro lado a densidade não se mostrou influente quanto aos aspectos qualitativos e quantitativos das ninhadas nem na alimentação entre os eventos reprodutivos.

A hipótese de que haveria influência no número de descendentes foi refutada em uma análise a curto prazo. Ao analisarmos a longo prazo podemos compreender que a hipótese é válida, onde o número de eventos reprodutivos foi afetado pela densidade, e ao fim do ciclo vital os indivíduos estabelecidos em pequenas agregações ou isolados terão o fitness superior ao dos que foram afetados pela alta densidade populacional de Tityus serrulatus. Outro fator que é interessante levarmos em consideração é que em ambiente natural o escorpião amarelo se abriga em bueiros, caixas de incêndio, cemitérios, sistemas de águas pluviais e entulhos, o que o possibilita deslocar-se para locais menos populosos, diminuindo assim os prejuízos causados por estar inserido em uma superpopulação.

Outros resultados observados neste estudo foram os casos de aborto, natimortos, canibalismo e o compartilhamento de prole, os três primeiros já sendo conhecidos para o gênero, porém o comportamento de aceitar filhotes oriundos de outras fêmeas é algo novo para esta espécie e assim cria a oportunidade para novos estudos, onde podem ser analisados aspectos comportamentais dos filhotes, adultos e o genótipo dos indivíduos que apresentam tal comportamento.

Por fim, esperamos que este trabalho possa estimular e abrir novas oportunidades para estudos com Tityus serrulatus, buscando entender melhor o comportamento deste animal, até mesmo para auxiliar políticas de saúde pública para o controle desta espécie tão adaptada ao meio urbano e cada vez mais em contato com o seres humanos. 


\section{REFERÊNCIAS}

Albuquerque, C. M. R. D., Barbosa, M. O. \& Iannuzzi, L. 2009. Tityus stigmurus (Thorell, 1876) (Scorpiones; Buthidae): response to chemical control and understanding of scorpionism among the population. Revista da Sociedade Brasileira de Medicina Tropical, 42(3): 255-259.

Alexander, R. D. 1974. The evolution of social behavior. Annual Review of Ecology and Systematics, 5(1): 325-383.

Anderson, M. 1984. The evolution of eusociality. Annual Review of Ecology and Systematics, 15(1): 165-189.

Begon M, Townsend C. A., Harper J. L. 2006 Ecology: From individuals to ecosystems. Wiley-Blackwell, $4^{\mathrm{o}}$ edition. 759 p.

Bilde, T. \& Lubin, Y. 2001. Kin recognition and cannibalism in a subsocial spider. Journal of Evolutionary Biology, 14(6): 959-966.

Both, C., \& Visser, M. E. 2000. Breeding territory size affects fitness: an experimental study on competition at the individual level. Journal of Animal Ecology, 69(6): 1021-1030.

Brach, V. 1977. Anelosimus studiosus (Araneae: Theridiidae) and the evolution of quasisociality in theridiid spiders. Evolution, 31(1): 154-161.

Brasil. 2009. Ministério da saúde. Secretaria de Vigilância em Saúde. Departamento de Vigilância Epidemiológica. Manual de controle de escorpiões / Ministério da saúde, secretaria de Vigilância em saúde, Departamento de Vigilância Epidemiológica. Brasília: Ministério da saúde. 72 p.

Brasil. 2015. Ministério da saúde. Secretaria de Vigilância em Saúde. Departamento de Vigilância Epidemiológica. http://portalsaude.saude.gov.br/index.php/oministerio/principal/leia-mais-o-ministerio/1019-secretaria-svs/vigilancia-de-a-az/animais-peconhentos-escorpioes/12-animais-peconhentos-escorpioes/13692-situacaoepidemiologica-dados. Acessado em 19 de fevereiro de 2017. 
Brazil, T. K. \& Porto. T.J. 2010. Os escorpiões. Salvador: Editora da Universidade Federal da Bahia. 84 p.

Brown, C. A. 2003. Offspring size-number trade-offs in scorpions: an empirical test of the van Noordwijk and de Jong model. Evolution, 57(9): 2184-2190.

Brown, C. A. 2004. Life histories of four species of scorpion in three families (Buthidae, Diplocentridae, Vaejovidae) from Arizona and New Mexico. Journal of Arachnology, 32(2): 193-207.

Brownell, P. \& Polis, G. A. 2001. Scorpion biology and research. Oxford University Press. $431 \mathrm{p}$.

Brusca, R., Brusca, G., \& Haver, N.J. 2003. Invertebrates. Sunderland, Massachusetts. 888 p.

Bucaretchi, F., Zambrone, F. A. D., Fonseca, M. R. C. C., Douglas, J. L. \& Tourinho, F. S. 1995. Severe scorpion envenomation in children caused by Tityus bahiensis and Tityus serrulatus. Toxicon, 33(3): 292-293.

Burgess, J. W. \& Uetz, G. W. 1982. Social spacing strategies in spiders. In P. N. Witt \& J. S. Rovner (eds.), Spider communication: mechanisms and ecological significance, pp. 317351. Princeton University Press.

Camargo, F. J., \& Ricciardi, A. 2000. Sobre la presencia de un escorpión Tityus serrulatus Lutz e Mello (Scorpiones, Buthidae) en la ciudad de Corrientes. In Comunicaciones Científicas y Tecnológicas. Universidad Nacional del Nordeste. $3 p$

Colombo, W. D. \& de Alencar, I. D. C. C. 2013. Etograma do escorpião amarelo Tityus serrulatus Lutz \& Mello 1922 (Scorpiones: Buthidae), em cativeiro. Comparative ethogram of the yellow scorpion Tityus serrulatus Lutz \& Mello 1922 (Scorpiones: Buthidae) in captivity. Bioscience Journal, 30(2): 576-581.

Cupo, P., Jurca, M., Azevedo-Marques, M. M., Oliveira, J. S. M. \& Hering, S. E. 1994. Severe scorpion envenomation in Brazil: clinical, laboratory and anatomopathological aspects. Revista do Instituto de Medicina Tropical de São Paulo, 36(1): 67-76. 
Darchen, R., \& Delage-Darchen, B. 1986. Societies of spiders compared to the societies of insects. Journal of Arachnology, 14(2): 227-238.

Eickstedt, V. R. D., Candido, D. M., Jorge, M. T., Albuquerque, M. J. \& Ribeiro, L. A. 1994. Escorpionismo no Estado de São Paulo: ocorrência de Tityus serrulatus e T. bahiensis, frequência de acidentes e gravidade dos envenenamentos. Revista do Instituto de Medicina Tropical de São Paulo. 27(1): 56.

Eickstedt, V. R. D., Ribeiro, L. A., Candido, D. M., Albuquerque, M. J., \& Jorge, M. T. 1996. Evolution of scorpionism by Tityus bahiensis Perty, 1833 and Tityus serrulatus Lutz \& Mello and geographical distribution of the two species in the state of São Paulo, Brazil. Journal of Venomous Animals and Toxins, 2(2): 92-105.

Enders, F. 1976. Clutch size related to hunting manner of spider species. Annals of the Entomological Society of America, 69(6): 991-998.

Futuyma, D. J. 2005. Evolution. Sinauer Associates, 603 p.

Gaffin, D. D., Bumm, L. A., Taylor, M. S., Popokina, N. V., \& Mann, S. 2012. Scorpion fluorescence and reaction to light. Animal Behaviour, 83(2): 429-436.

Gouge, D. H. \& Snyder, J. L. 2005. Parasitism of bark scorpion Centruroides exilicauda (Scorpiones: Buthidae) by entomopathogenic nematodes (Rhabditida: Steinernematidae; Heterorhabditidae). Journal of Economic Entomology, 98(5): 14861493.

Hamilton, W. D. 1971. Geometry for the selfish herd. Journal of Theoretical Biology, 31(2): 295-311.

Higashi, G. A. \& Rovner, J. S. 1975. Post-emergent behavior of the juvenile lycosid spiders. Bulletin of the Britsh Arachnological Society, 3: 113-119.

Killebrew, D. W. \& Ford, N. B. 1985. Reproductive tactics and female body size in the green lynx spider, Peucetia viridans Hentz, 1832 (Araneae, Oxyopidae). Journal of Arachnology, 13(3): 375-382. 
Knox, M. B. 1997. Estudo dos escorpiões em ambientes naturais e urbanos do DF: abordagem ecológica de duas espécies Tityus fasciolatus Pessoa, 1935 e Tityus serrulatus Lutz \& Mello, 1922. Dissertação de Mestrado em Ecologia, Universidade de Brasília. 60 p.

Kullmann, E. J. 1972. Evolution of social behavior in spiders (Araneae; Eresidae and Theridiidae). American Zoologist, 12(3): 419-426.

Lourenço, W. R. \& Cloudsley-Thompson, J. L. 1999. Discovery of a sexual population of Tityus serrulatus Lutz \& Melo, 1922, one of the morphs within the complex Tityus stigmurus (Scorpiones, Buthidae). Journal of Arachnology, 27(1): 154-158.

Lourenço, W. R. \& Cuellar, O. 1995. Scorpions, scorpionism, life history strategies and parthenogenesis. Journal of Venomous Animals and Toxins, 1(2): 51-62.

Lourenço, W. R. \& Eickstedt, V. V. 1981. A propósito da indicação de um neótipo para Tityus serrulatus Lutz \& Mello, 1922 (Scorpiones; Buthidae). 44(45): 181-190.

Lourenço, W. R. 2000. Reproduction in scorpions, with special reference to parthenogenesis. In S. Toft \& N. Scharff (eds.) European arachnology, pp. 71-85. Aarhus University Press. European Arachnology.

Lourenço, W. R. 2008. Parthenogenesis in scorpions: Some history-new data. Journal of Venomous Animals and Toxins, 14(1): 19-44.

Lourenço, W. R., Knox, M. B. \& Yoshizawa, A. C. 1994. L'invasion d'une communauté au stade initial d'une succession secondaire par une espèce parthénogénétique de scorpion. Biogeographica, 70(2): 77-91.

Lourenço, W. R. 1991. Biogeographie evolutive, ecologie et les strategies biodemographiques chez les scorpions neotropicaux. C.R. Soc. Biogeogr., 67 (4): 171-190

Lourenço, W. R. 2002. Scorpions of Brazil. Paris, Les editions de l'If. 230 p.

MacArthur, R. H. \& Wilson, E. O. 1967. The theory of island biogeography. Princeton, New Jersey. $224 \mathrm{P}$. 
Mahsberg, D. 1990. Brood care and family cohesion in the tropical scorpion Pandinus imperator Koch, 1841. (Scorpiones: Scorpionidae). Acta Zoologica Fennica, 190: 267272.

Matthiesen, F. A. 1971. The breeding of Tityus serrulatus Lutz \& Mello 1922, in captivity (Scorpiones, Buthidae). Revista Brasileira de Pesquisas Médicas e Biológicas, 4(4-5): 299-300.

Matthiesen, F. A. 1984. Revisão sobre parasitas e predadores de escorpiões. Naturalia, 9, 1-5.

Matthiesen, F.A. 1962. Parthenogenesis in scorpions. Evolution 16 (2): 255-256.

Mineo, M. F., Franco-Assis, G. A. \& Del-Claro, K. 2003. Repertório comportamental do escorpião amarelo Tityus serrulatus Lutz \& Mello 1922 (Scorpiones, Buthidae) em cativeiro. Revista Brasileira de Zoociências, 5(1): 23-31.

Motta, P.C. 2014. Aracnídeos do Cerrado, 1.ed. Rio de Janeiro. Editora Technical books. 209 p.

Outeda-Jorge, S., Mello, T. \& Pinto-da-Rocha, R. 2009. Litter size, effects of maternal body size, and date of birth in South American scorpions (Arachnida: Scorpiones). Zoologia (Curitiba), 26(1): 45-53.

Pasquet, A., Trabalon, M., Bagneres, A. G. \& Leborgne, R. 1997. Does group closure exist in the social spider Anelosimus eximius Keyserling, 1884? Behavioural and chemical approach. Insectes Sociaux, 44(2): 159-169.

Polis, G. A. \& Farley, R. D. 1979. Behavior and ecology of mating in the cannibalistic scorpion, Paruroctonus mesaensis Stahnke (Scorpionida: Vaejovidae). Journal of Arachnology, 7(1): 33-46.

Polis, G. A. \& Farley, R. D. 1980. Population biology of a desert scorpion: survivorship, microhabitat, and the evolution of life history strategy. Ecology, 61(3): 620-629.

Polis, G. A. \& Lourenço, W. R. 1986. Sociality among scorpions. Actas X Congreso Internacional de Aracnologia. Jaca/Espana, 1: 111-115.

Polis, G. A. 1990. The Biology of Scorpions. California, Stanford University Press. 587 p. 
Polis, G.A. \& W.D. Sissom. 1990. Life history. In P.A. Gary. (ed.), The Biology of Scorpions, pp. 161-223. Stanford University Press.

Pulliam, H. R. \& Caraco, T. 1984. Living in groups: is there an optimal group size. Behavioural Ecology: an evolutionary approach, 2: 122-147.

Rouaud, C., Huber, D. \& Lourenço, W. R. 2000. Life history of Caribetityus elli (Armas \& Marcano Fondeur, 1992) from the Dominican Republic (Scorpiones, Buthidae). In S. Toft \& N. Scharff (eds.) European arachnology, pp. 87-90. Aarhus University Press.

Rypstra, A. L. 1985. Aggregations of Nephila clavipes Linnaeus, 1767 (Araneae, Araneidae) in relation to prey availability. Journal of Arachnology, 13(1): 71-78.

Santana-Neto, P. L., Albuquerque, C. M. R., Silva, A. P. P., Svedese, V. M. \& Lima, E. A. L. A. 2010. Natural occurrence of the Fusarium solani on Tityus stigmurus (Thorell, 1876) (Scorpiones: Buthidae). Brazilian Journal of Biology, 70(1): 151-153.

Santos, M. D. S., Porto, T. J., Lira-da-Silva, R. M. \& Brazil, T. K. 2014. Description of the male of Tityus kuryi Lourenço, 1997 and notes about males of Tityus stigmurus (Thorell, 1877) and Tityus serrulatus Lutz \& Mello, 1922 (Scorpiones, Buthidae). ZooKeys, (435): 49-61.

Schneider, M. C. \& Cella, D. M. 2010. Karyotype conservation in 2 populations of the parthenogenetic scorpion Tityus serrulatus (Buthidae): rDNA and its associated heterochromatin are concentrated on only one chromosome. Journal of Heredity, 101(4): 491-496.

Shivashankar, T. 1994. Advanced sub social behaviour in the scorpion Heterometrus fulvipes Brunner (Arachnida). Journal of Biosciences, 19(1): 81-90.

Silva, A. M., Bernarde, P. S. \& de Abreu, L. C. 2015. Accidents with poisonous animals in Brazil by age and sex. Journal of Human Growth and Development, 25(1): 54-62.

Souza, C. A. R., Candido, D. M., Lucas, S. M. \& Brescovit, A. D. 2009. On the Tityus stigmurus complex (Scorpiones, Buthidae). Zootaxa, (1987): 1-38.

Uetz, G. W. \& Hieber, C. S. 1994. Group size and predation risk in colonial web-building spiders: analysis of attack abatement mechanisms. Behavioral Ecology, 5(3): 326-333. 
Uetz, G. W. \& Hieber, C. S. 1997. Colonial web-building spiders: balancing the costs and benefits of group-living. The evolution of social behaviour in insects and arachnids. Cambridge University Press. 552 p.

Uetz, G. W., Boyle, J. A., Y. Hieber, C. S. \& Wilcox, R. S. 2002. Antipredator benefits of group living in colonial web-building spiders: the 'early warning' effect. Animal Behaviour, 63(3): 445-452.

Wilson, E. O. 1971. The Insect Societies. Cambridge. Harvard University Press. 562 p.

Wilson, E. O. 1975. Sociobiology: The new synthesis. Cambridge. Harvard University Press. $720 \mathrm{p}$. 